\title{
Influence of genetics
} and the pre-vaccination blood transcriptome on the variability of antibody levels after vaccination against Mycoplasma hyopneumoniae in pigs

Fany Blanc ${ }^{1 *} \mathbb{D}$, Tatiana Maroilley ${ }^{1} \mathbb{B}$, Manuel Revilla ${ }^{1} \mathbb{D}$, Gaëtan Lemonnier $^{1}$, Jean-Jacques Leplat ${ }^{1}$,

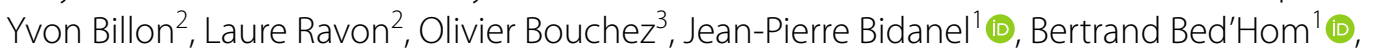

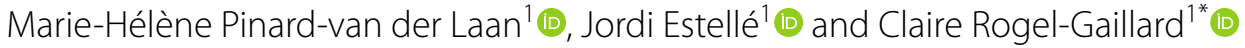

\begin{abstract}
Background: The impact of individual genetic and genomic variations on immune responses is an emerging lever investigated in vaccination strategies. In our study, we used genetic and pre-vaccination blood transcriptomic data to study vaccine effectiveness in pigs.

Results: A cohort of 182 Large White pigs was vaccinated against Mycoplasma hyopneumoniae (M. hyo) at weaning (28 days of age), with a booster 21 days later. Vaccine response was assessed by measuring seric M. hyo antibodies (Ab) at 0 (vaccination day), 21 (booster day), 28, 35, and 118 days post-vaccination (dpv). Inter-individual variability of M. hyo Ab levels was observed at all time points and the corresponding heritabilities ranged from 0.46 to 0.57 . Ab persistence was higher in females than in males. Genome-wide association studies with a $658 \mathrm{~K}$ SNP panel revealed two genomic regions associated with variations of $M$. hyo Ab levels at $21 \mathrm{dpv}$ at positions where immunity-related genes have been mapped, DAB2IP on chromosome 1, and ASAP1, CYRIB and GSDMC on chromosome 4. We studied covariations of Ab responses with the pre-vaccination blood transcriptome obtained by RNA-Seq for a subset of 82 pigs. Weighted gene correlation network and differential expression analyses between pigs that differed in Ab responses highlighted biological functions that were enriched in heme biosynthesis and platelet activation for low response at $21 \mathrm{dpv}$, innate antiviral immunity and dendritic cells for high response at 28 and $35 \mathrm{dpv}$, and cell adhesion and extracellular matrix for high response at $118 \mathrm{dpv}$. Sparse partial least squares discriminant analysis identified 101 genes that efficiently predicted divergent responders at all time points. We found weak negative correlations of $M$. hyo Ab levels with body weight traits, which revealed a trade-off that needs to be further explored.
\end{abstract}

Conclusions: We confirmed the influence of the host genetics on vaccine effectiveness to M. hyo and provided evidence that the pre-vaccination blood transcriptome co-varies with the Ab response. Our results highlight that both

*Correspondence: fany.blanc@inrae.fr; claire.rogel-gaillard@inrae.fr

1 Université Paris-Saclay, INRAE, AgroParisTech, GABI, 78350 Jouy-en-Josas, France

Full list of author information is available at the end of the article

c) The Author(s) 2021. This article is licensed under a Creative Commons Attribution 4.0 International License, which permits use, sharing, adaptation, distribution and reproduction in any medium or format, as long as you give appropriate credit to the original author(s) and the source, provide a link to the Creative Commons licence, and indicate if changes were made. The images or other third party material in this article are included in the article's Creative Commons licence, unless indicated otherwise in a credit line to the material. If material is not included in the article's Creative Commons licence and your intended use is not permitted by statutory regulation or exceeds the permitted use, you will need to obtain permission directly from the copyright holder. To view a copy of this licence, visit http://creativeco mmons.org/licenses/by/4.0/. The Creative Commons Public Domain Dedication waiver (http://creativecommons.org/publicdomain/ zero/1.0/) applies to the data made available in this article, unless otherwise stated in a credit line to the data. 


\section{Background}

Sustainability is one of the main current challenges in livestock farming. In this context, reducing the use of antibiotics and anti-microbials has become a major concern. This can be addressed by considering that animals continually interact with a dynamic and potentially pathogenic ecosystem. Increasing vaccination efficiency is one of the avenues explored to promote sustainable livestock production. To achieve this, it is necessary to better understand the mechanisms that underlie host-pathogens interactions, to develop new vaccines and vaccination strategies, and also to consider genetic improvement of the host response to vaccination and management of its variability $[1,2]$.

Mycoplasma hyopneumoniae (M. hyo) bacteria are known to cause enzootic pneumonia, a chronic respiratory disease in pigs, and play a primary role in the porcine respiratory disease complex [3]. M. hyo infections cause significant economic losses due to the costs of treatments, reduced animal performance by decreasing growth, and increased mortality from secondary infections [4]. Commercial vaccines are effective in preventing and reducing the severity of lung lesions, and thus in improving daily weight gain and slaughter weight [5-8]. However, they do not reduce the transmission of the pathogen significantly $[7,9]$. Therefore, improving vaccination efficacy to $M$. hyo is still an important issue.

Systems vaccinology and vaccinomics, which consist of merging -omics data to comprehensively assess biological systems in response to vaccination, are new approaches that have been proposed in human vaccinology to enhance insights into the evaluation of immune responses and adverse events, and the development of new vaccine candidates $[10,11]$. Immunogenetic studies in humans have revealed that single nucleotide polymorphisms (SNPs) in human leukocyte antigen class I and class II, cytokine, cytokine receptor, and innate immune response (e.g., toll-like receptor) genes may partly account for the inter-individual variability of the immune response to various vaccinations (measles and rubella [1, 12-16], hepatitis B [1, 17-19], influenza [20], smallpox [21] or Bacillus anthracis [22]). In humans, host genetics has been reported to influence the persistence of specific antibodies $(\mathrm{Ab})$ throughout life, after vaccination against tetanus toxoid, influenza $B$ virus, and capsular group $\mathrm{C}$ meningococcal during childhood [23]. In livestock animals, the role of host genetics in the variability of $\mathrm{Ab}$ response to vaccines has been documented for respiratory syncytial virus vaccine in bovine [24] and for Newcastle disease virus vaccine in chicken [25]. In pigs, across-breed variability of response levels to vaccine against Aujeszky's virus disease has been reported [26]. Within-population variability has been shown for $\mathrm{Ab}$ response to vaccines against influenza [27] and porcine reproductive and respiratory syndrome [28] viruses, and tetanus bacteria [29], and to the bacterial antigens K88ab, K88ac, and O149 [30]. We and others have also reported individual variability of serum $M$. hyo-specific $\mathrm{Ab}$ induced after vaccination in various populations [31, 32].

Blood is an accessible fluid that reflects the status of the immune system [33]. Thus, in vaccine research, it serves as a surrogate tissue to identify potential markers of vaccine-induced responses. In swine, we have shown that the peripheral blood transcriptome reflects variations in innate and adaptive immunity traits [34]. In humans, blood transcriptomic profiling has identified both early innate $[35,36]$ and concomitant adaptive humoral immunity gene signatures after vaccination [37]. In particular, $\mathrm{Li}$ et al. [38] defined early transcriptional signatures of $\mathrm{Ab}$ responses that were derived from a systems biology study. Such studies have also been recently conducted in sheep $[39,40]$ and pigs [41-43], and have provided insights into the pathways involved in vaccination responses. However, to date, the underlying determinants of immune capacity that are involved in vaccination responses have not been identified.

In this study, our aim was to characterize individual variability of vaccine response to $M$. hyo in pigs and to identify genetic parameters and baseline blood transcriptomic profiles that could predispose to effective response to vaccination and predict associated $\mathrm{Ab}$ response levels. Thus, we combined data from high-density genotyping, the transcriptome of blood collected before vaccination, and $M$. hyo-specific Ab levels at various time points after vaccination.

\section{Methods}

\section{Animal design, zootechnical traits, and sampling}

In total, 48 litters of Large White pigs were produced in five batches and raised without antibiotic treatment on the GenESI, INRAE, Pig Innovative Breeding Experimental Facility (https://doi.org/10.15454/1.5572415481 185847E12). Sows $(n=47)$ were inseminated with boar semen $(n=48)$ that was selected to maximize genetic variability, with one sow inseminated for two parities. 
From each litter, three to four piglets of each sex were chosen based on their weight at 21 days, taking care to represent average litter weight piglets and avoid animals with a too low weight. This resulted in a set of 278 piglets (145 uncastrated males and 133 females) that defined the experimental population. At random four to five piglets per litter were vaccinated against $M$. hyo (Stellamune, Pfeizer), and the remaining piglets (one or two animals per litter) were not vaccinated. In total, the experimental population included 203 vaccinated animals and 75 control non-vaccinated animals. The experimental design with the associated measures at different time points is summarized in Fig. 1a. A first injection was administered at $0 \mathrm{dpv}$, corresponding to the day of weaning (at 28 days of age on average, from 24 to 31 days). A booster vaccination injection was given at $21 \mathrm{dpv}$. A small subset of animals was removed from the initial population due to farming problems that led to morbidity and premature death ( $\mathrm{n}=13$ vaccinated and 11 controls) or to no response to vaccination during the experiment $(n=4)$. The latter four animals were not included because we could not conclude whether they were non-responders or whether the vaccination injection had failed.

The animals were raised under standard conditions in pens of 20 to 30 animals during the post-weaning period (from around 28 to 68 days of age) and in pens of 10 to 12 animals during the growth period (from around 68 to 146 days of age). They all received the same standard commercial diets. The final dataset comprised 186 piglets vaccinated against $M$. hyo and 64 control nonvaccinated piglets, of which 170 and 61, respectively, were monitored until $118 \mathrm{dpv}$. The final individual dataset is in Additional file 1: Table S1. Body weights (BW) were determined at different time points: at birth, 7 days before weaning (dbw) at around 21 days of age, at weaning at around 28 days of age (corresponding to $0 \mathrm{dpv}$ ), at

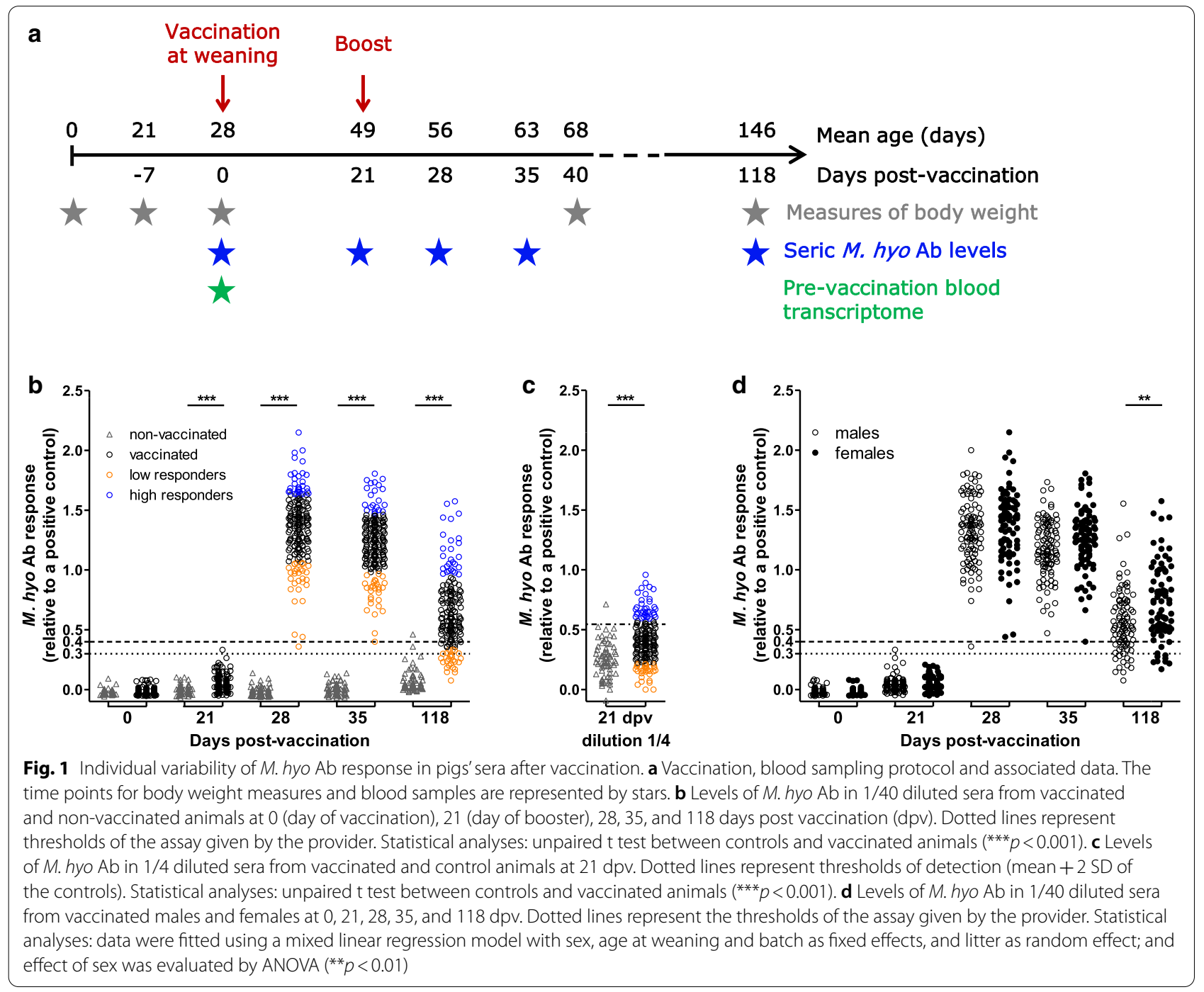


the end of the post-weaning period (corresponding to $40 \mathrm{dpv}$ ) at around 68 days of age, and at the end of the experiment, before slaughter (corresponding to $118 \mathrm{dpv}$ ) at around 146 days of age. Average daily gain (ADG) was calculated from 0 to $40 \mathrm{dpv}$ (ADG 0-40 dpv) and from 40 to $118 \mathrm{dpv}$ (ADG 40-118 dpv).

Peripheral blood was sampled from the jugular vein at different time points using dry tubes (Becton Dickinson) for serum preparation $(0,21,28,35$, and $118 \mathrm{dpv})$, EDTAcoated tubes (Becton Dickinson) for DNA extraction (0 dpv), and Tempus tubes (Thermo Fisher) for RNA extraction $(0 \mathrm{dpv})$. Blood samples were stored at $-20^{\circ} \mathrm{C}$ (EDTA tubes) or at $-80{ }^{\circ} \mathrm{C}$ (Tempus tubes) prior to DNA or RNA extraction, respectively. Peripheral blood was also sampled from sows on dry tubes during the week before parturition to check that they were seronegative for $M$. hyo-specific Ab.

\section{Measurement of $M$. hyo-specific Ab levels and classification of animals based on $A b$ response}

The levels of $M$. hyo-specific Ab were measured by using a commercial ELISA test (IDEXX M. hyo Ab test, IDEXX Europe B.V., The Netherlands) and running duplicates of sera diluted $1 / 40$ for all time points $(0,21,28,35$, and $118 \mathrm{dpv})$. At $21 \mathrm{dpv}, M$. hyo-specific Ab were also measured with sera diluted $1 / 4$. Ab levels were calculated by dividing the absorbance of the samples ( $\mathrm{S}$, corrected by subtraction of the mean negative control absorbance) by the mean absorbance of the positive control (P, corrected by subtraction of the mean negative control absorbance), which resulted in an S/P value following the IDEXX procedure. Given the thresholds provided by IDEXX, samples with $\mathrm{S} / \mathrm{P}$ values higher than 0.4 , within the range from 0.3 to 0.4 , or lower than 0.3 , were assessed as positive, suspect, or negative for $M$. hyo $\mathrm{Ab}$, respectively.

To carry out differential analyses between animals with high and low vaccine responses, we identified extreme groups for $M$. hyo-specific Ab levels at 21, 28, 35, and $118 \mathrm{dpv}$, using the $\mathrm{S} / \mathrm{P}$ values obtained for the whole pig population at each time point $(\mathrm{n}=186$ at 21,28 , and 35 $\mathrm{dpv}$ and $\mathrm{n}=170$ at $118 \mathrm{dpv}$ ). High (low) responders corresponded to pigs with an Ab response higher (lower) than the mean plus (minus) one standard deviation (SD) $(\mathrm{n}=34,30,22$, and 27 for high responders, colored in blue in Fig. 1a, b, and $\mathrm{n}=32,29,28$, and 25 for low responders, colored in orange in Fig. $1 \mathrm{a}, \mathrm{b}$ at 21, 28, 35 , and $118 \mathrm{dpv}$, respectively). Positive (pos) and negative (neg) animals were defined at $118 \mathrm{dpv}$ based on the thresholds of the $\mathrm{Ab}$ test given by the manufacturer (neg: $\mathrm{S} / \mathrm{P}$ value $<0.3, \mathrm{n}=19$, pos: $\mathrm{S} / \mathrm{P}$ value $>0.4, \mathrm{n}=136$ ). For $\mathrm{Ab}$ response at $21 \mathrm{dpv}$, the mean plus $2 \mathrm{SD}$ of the values obtained for non-vaccinated control animals were used to determine detection thresholds $(0.07$ at $1 / 40$ dilution and 0.545 at $1 / 4$ dilution). Animals for which values were below vs above these thresholds at both dilutions were classified as negative $(n=134)$ vs positive $(n=32)$. Animal groups at each time point are in Additional file 1: Table S1 and descriptive statistics of the groups are in Additional file 1: Table S2.

\section{Effect of zootechnical parameters on vaccination response and of vaccination on body weight}

Unless otherwise notified, all data analyses were conducted with the R software (v3.6.1) [44]. The effects of different zootechnical parameters on $M$. hyo Ab responses were evaluated with a linear mixed model using the lmer function of the lme4 (v1.1-21) R package [45], with sex (two levels) and batch (five levels) as fixed effects, age at weaning (between 24 and 31 days) as a linear covariate, and litter (48 levels) as a random effect. To evaluate the effect of vaccination on weight traits, vaccine groups (vaccinated vs non-vaccinated; or high vs low; or negative vs positive) were also included in the model as fixed effects. $P$-values for fixed effects were obtained using the lmerTest package (v3.1-1) [46] by type III ANOVA tables, with Satterthwaite's approximation to degrees of freedom using the ANOVA function, while $p$-values for random effects were calculated by the likelihood ratio test using the rand function. Pairwise comparisons with Tukey's adjustment were performed to assess the differences between batches, using the emmeans function of the emmeans package (v1.5.2-1). A significance level of 0.05 was applied. Pearson's correlation matrices were built with the corrplot R package (v0.84). Correlations of the repeated measures of $\mathrm{Ab}$ response levels at the different time points post-vaccination were also calculated using a linear mixed model with dpv as fixed effect, animal as random effect, and an autoregressive correlation structure of order 1 (corCAR1 function) across dpv, using the nlme package (v3.1-141). Principal component analyses (PCA) were performed with the FactoMineR $\mathrm{R}$ package (v2.1) [47] and the results were visualized based on the factoextra R package (v1.0.6).

\section{Estimation of heritabilities}

Genetic parameters (heritabilities and genetic correlations) were estimated using the restricted maximum likelihood methodology applied to a multivariate mixed linear model with the same fixed effects and covariates (sex, batch and age at weaning) as above, and the additive genetic value of each animal and a residual error as random effects, which is the so-called animal model, where the vector of additive genetic values is assumed to be proportional to the numerator relationship matrix built from pedigrees. Computations were performed using the VCE6 software [48]. 


\section{Genome-wide association studies (GWAS)}

Vaccinated pigs $(n=186)$ were genotyped with a highdensity SNP panel (Affymetrix AXIOM PIG HD, $658 \mathrm{~K}$ SNP). Genotyping of four pigs (2.1\%) did not pass various internal quality controls $(\mathrm{QC})$ that identify poor quality samples using the Axiom Suite [Dish QC $(\mathrm{n}=2)$ and sample QC call rate test $(n=2)]$. Among the genotypes for the 182 remaining animals that passed plate QC (see Additional file 1: Table S1), only annotated autosomal SNPs were kept for analysis ( $\mathrm{n}=598,138$; Axiom_PigHD_ v1.na35.r4.a2.annot.csv annotation file). The check. marker function of the GenABEL package (v1.8-0) in $\mathrm{R}$ was applied to filter out SNPs with a minor allele frequency lower than $5 \%(89,175$ SNPs excluded), a call rate lower than 95\% (58,869 SNPs excluded), or SNPs that departed from Hardy-Weinberg equilibrium (FDR lower than $0.1 ; 41,149$ SNPs excluded). After applying these QC measures, 425,567 SNPs on 182 animals were retained for GWAS. Overall, the QC analysis of the genotyping data did not identify outlier animals and the genomic kinship coefficients between individuals were consistent with the known pedigrees. GWAS were performed with the RepeatABEL R package (v1.1) [49], by using a linear mixed model with batch and sex as fixed effects, age at weaning as a linear covariate, and litter and the genomic kinship matrix (built with the ibs function) as random effects. A significance level of 0.05 and a suggestive significance level of 0.1 were applied. Finally, the detected associated regions were mapped to the pig genome assembly available at the UCSC Genome Browser on Feb. 2017 (Sscrofa11.1).

\section{Blood transcriptome by RNA-Seq}

RNA from blood samples that were collected in Tempus tubes prior vaccination at $0 \mathrm{dpv}$ was extracted from a subset of 85 vaccinated pigs (see Additional file 1: Table S1), using the Norgen Preserved Blood RNA Purification Kit I (adapted to blood samples collected in Tempus tubes) according to the manufacturer's instructions. Concentration of the extracted RNA was measured with a NanoDrop 2000 spectrophotometer (89.4 \pm $26.0 \mu \mathrm{g}$ were obtained per sample) and RNA integrity was assessed by an Agilent 2100 Bioanalyzer, using the eukaryote total RNA 6000 Nano Kit (RIN obtained were $8.0 \pm$ 0.6 , ranging from 7.1 to 9.3 ).

Libraries were prepared from $1 \mu \mathrm{g}$ of total RNA with the Illumina TruSeq stranded total RNA with Ribo-Zero Globin sample preparation kit. Following the manufacturer's protocol, ribosomal and globin RNA were removed by depletion and the remaining coding and non-coding RNA was used as input for library preparation. RNA was fragmented using Illumina's fragmentation enzyme mix (Elute, Prime, Fragment Mix) for $8 \mathrm{~min}$ at $94{ }^{\circ} \mathrm{C}$. For synthesis of the first strand, $1 \mu \mathrm{L}$ of SuperScript II Reverse Transcriptase was mixed with $9 \mu \mathrm{L}$ of Illumina's First Strand Mix with actinomycin D, and then $8 \mu \mathrm{L}$ of this mix were added to the fragmented RNA, and PCR was carried out in a thermocycler that was programmed as indicated in the TruseqRNA protocol. To generate double strand (ds) cDNA, $20 \mu \mathrm{L}$ of Illumina's Second Strand mix were mixed with the first strand cDNA and incubated for one hour at $16^{\circ} \mathrm{C}$. Then, $90 \mu \mathrm{L}$ of AMPure XP beads were used to purify the ds cDNA that was eluted in $15 \mu \mathrm{L}$ of Illumina's resuspension buffer. The ds cDNA was end-repaired, adenylated, and then Illumina adapters were added, as indicated in the TruSeq stranded mRNA protocol. The prepared libraries were quality-checked with the high sensitivity D1000 screen Tape (Agilent Tape Station 2200), quantified with Qubit (ThermoFisher), and 12-plex pooled. The pooled libraries were quantified with the Qubit dsDNA HS (High Sensitivity) Assay kit and sequenced on the GeT-PlaGe core facility (INRAE, https://doi.org/10.15454/1.5572370921 303193E12) on the Illumina Hiseq3000 sequencer with a 150PE module, with each pool run in two Hiseq3000 lanes.

The reads were mapped to the pig genome assembly Sscrofa11.1 (Ensembl v90 release) by using TopHat (v2.1.0), and the read counts for each gene were obtained by using htseq_count (v0.6.1.p1). Overall, the RNA-Seq data provided a sufficient number of reads per sample (mean number of reads larger than $60 \times 10^{6}$ ). Three animals with a total number of reads smaller than 20 million were excluded. Thus, the final dataset for the transcriptome analysis included 82 vaccinated pigs, of which 15 , 14,11 , and 11 were high responders at $21,28,35$, and 118 dpv, respectively, $15,23,19$, and 13 were low responders at $21,28,35$, and $118 \mathrm{dpv}$, respectively, and 55 and 10 were negative, and 14 and 64 were positive at 21 and 118 dpv, respectively. These pigs were representative of the corresponding groups from the whole population, showing equivalent means of $\mathrm{Ab}$ levels (see Additional file 1: Table S2).

\section{Weighted gene correlation network analysis (WGCNA) and correlation with vaccine-induced $A b$ responses}

WGCNA [50] was conducted in R to find clusters of highly correlated genes within the RNA-Seq dataset. Read counts per gene were filtered by retaining only the genes with more than 1 count per million and more than 10 reads for at least one third of the animals. Read counts were then normalized with the calcNormFactors function implemented in the edgeR package (v3.26.6). Finally, limma's voom function (v3.40.6) was used to fit a generalized linear regression model to correct the data with sex and batch as fixed effects, and age at weaning 
as a linear covariate. Samples were then clustered based on their Euclidean distance (hclust function of fastcluster package v1.1.25) and six outliers were removed (SPH_034, SPH_058, SPH_084, SPH_193, SPH_195, and SPH_417). Thus, 76 samples were used for analysis. Block-wise network construction and module detection were carried out with the WGCNA package (v1.68) in two blocks using the blockwiseModules function with a threshold power of 6 , a height of 0.25 , a deep split level of 2 , a reassign threshold of 0.2 , and a minimum module size of 30 . The eigenmodules (essentially the first principal component of the modules, which can be used as a synthesis often referred to as a "signature" of the module gene expression) were then correlated with $\mathrm{Ab}$ responses. Modules that were correlated (Pearson correlation) with the $\mathrm{Ab}$ responses with a $p$-value lower than 0.05 were considered significantly correlated.

\section{RNA-Seq-based differential expression analyses of blood genes between pigs that differed in $\mathrm{Ab}$ responses to vaccine}

Differential expression (DE) analyses were conducted using the edgeR package (v3.26.6) in R. Read counts were filtered, normalized, and corrected for sex, age at weaning and batch effects as described for the WGCNA analysis. Then, likelihood ratio tests were performed to test, for each gene, the differential expression between extreme groups. The $p$-values were adjusted using the false discovery rate (FDR) method [51] and a significance level of 0.05 and a suggestive significance level of 0.1 were applied.

\section{Feature set enrichment analyses (FSEA)}

FSEA were performed with the $\mathrm{R}$ package tmod (v0.40) [52]. Hypergeometric tests were used to determine the enrichment of each WGCNA module that was significantly correlated with $\mathrm{Ab}$ responses (foreground set) in the total RNA-Seq gene set (background set). The coincident extreme ranks in numerical observations (CERNO) method was used to analyze the feature set enrichment using lists of genes obtained from the DE analyses and ranked by the absolute logarithm of fold change (logFC). To interpret the feature set enrichments, we used gene collections consisting of the blood transcriptomic modules (BTM) and signatures annotated by Li et al. [38], which were adapted by replacing human genes with their corresponding genes in pigs by Matthijs et al. [43], and FSEA were visualized with tmodPanelPlot.
Sparse partial least square-discriminant analysis (sPLS-DA) and PLS-DA

Sparse partial least square-discriminant analyses (sPLSDA) [53] were performed with the mixOmics $R$ package (v6.10.8) to identify genes that were expressed in blood before vaccination and that were the most discriminative features of the response to vaccination. Read counts were filtered, normalized, and corrected for sex, age at weaning, and batch effects, as described for the WGCNA analysis. The classification performance (error rate) was estimated with the function tune.splsda of the mixOmics R package. The tuning was first performed one component at a time, with a maximum of ncomp $=3$ and with 5 to 95 (step of 5) genes to test per component, and fivefold cross-validation repeated 100 times. In all analyses, one component was sufficient to provide the lower error rates. The optimal number of genes to select was then refined by performing another tuning in a more restricted range of genes to test, based on the error rate of the obtained profiles and with a maximum of 25 genes (step of 1), and fivefold cross-validation repeated 100 times. The final models included one component and the determined number of genes to be selected that led to the best performance for predicting the classification of animals in high vs low Ab responders at 21, 28, 35, and 118 $\mathrm{dpv}$ and positive vs negative $\mathrm{Ab}$ responders at 21 and 118 dpv. The set of predictive genes was defined by combining all these genes, and PLS-DA were finally performed to evaluate the predictive capacities of this final set of 101 genes.

\section{Results}

Individual variability of specific antibody response after $M$. hyo vaccination

All individual data and metadata are in Additional file 1: Table S1. The $M$. hyo-specific Ab response was monitored by measuring seric $M$. hyo-specific IgG levels at four time points, corresponding to three physiological steps of the humoral antibody response: early response after one injection of vaccine at $21 \mathrm{dpv}$ ( 49 days of age), maximum intensity of the response after the booster vaccination at 28 and $35 \mathrm{dpv}$ (56 and 63 days of age, respectively), and persistence of the $\mathrm{Ab}$ response until slaughter at $118 \mathrm{dpv}$ (146 days of age) (Fig. 1a). At $21 \mathrm{dpv}$, M. hyo $\mathrm{Ab}$ levels were significantly higher in vaccinated than in control animals but only one animal reached the threshold that indicated a $M$. hyo Ab response (Fig. 1b). Thus, at this early time point, we ran the assay with more concentrated sera (1/4 dilution, Fig. 1c) to better assess the variability among animals. At this dilution, $M$. hyo $\mathrm{Ab}$ levels were also significantly higher in vaccinated than in control animals. M. hyo Ab response reached maximum 
intensity at $28 \mathrm{dpv}$ for $79 \%$ of animals and at $35 \mathrm{dpv}$ for the other animals. At $118 \mathrm{dpv}, M$. hyo Ab levels remained above the threshold for $80 \%$ of the vaccinated pigs, which indicated a persisting humoral response for these animals. Among the other animals, 8.2 and $11.8 \%$ had suspect or negative $M$. hyo Ab levels, respectively.

We observed a high individual variability of the $M$. hyo Ab levels at each time point (Fig. $1 \mathrm{~b}$ and Table 1). The coefficients of variation (CV) were equal to $46 \%$ at early (21 dpv, serum dilution 1/4) and late time points (118 $\mathrm{dpv}$ ), and 20 and $21 \%$ at the maximum response intensity $(28$ and $35 \mathrm{dpv})$. At $21 \mathrm{dpv}$, the mean values of seric $\mathrm{Ab}$ levels with the 1/40 dilution were very low compared to the other values, with a CV that reached $151 \%$ (Table 1). In the next steps, for that time point, we used only the $\mathrm{Ab}$ levels measured with the $1 / 4$ dilution, which provided a better range of individual observations.

We assessed the effect of known factors that included sex, age at weaning, batch, and litter on $M$. hyo Ab levels. Batch had a significant $(p$-values $<0.05)$ effect at 28 and $118 \mathrm{dpv}$, litter at $21 \mathrm{dpv}$, and sex at $118 \mathrm{dpv}$ (see
Additional file 1: Table S3). Ab levels of animals from B_1602 were lower than those from B_1611 at $28 \mathrm{dpv}$ and lower than those from B_1604 at $118 \mathrm{dpv}$ ( $p$-values $<0.05$ ). Please note that females exhibited $30 \%$ higher levels of specific $\mathrm{Ab}$ in response to vaccination at $118 \mathrm{dpv}$ than males (see Additional file 1: Table S3) and Fig. 1d.

\section{Correlation between $M$. hyo Ab levels at different time points}

M. hyo Ab levels at different time points were positively correlated with one another (Fig. 2a). Ab levels at 28 and $35 \mathrm{dpv}$ were highly correlated with each other $(\mathrm{r}=0.84)$ and were correlated with $\mathrm{Ab}$ levels at $118 \mathrm{dpv}(\mathrm{r}=0.62$ and 0.71 , respectively). Ab levels at $21 \mathrm{dpv}$ were moderately correlated with later time point responses ( $\mathrm{r}$ ranging from 0.27 to 0.3 ). Since $M$. hyo Ab levels at different time points can be considered as repeated measurements, temporal correlations were evaluated and were found to be positive, ranging from 0.46 to 0.68 (see Additional file 1: Table S4). In a principal component analysis (PCA) of $M$. hyo Ab levels at all time points, animals were

Table 1 Descriptive statistics and heritability estimates of $M$. hyo Ab vaccine response at different days post-vaccination (dpv)

\begin{tabular}{|c|c|c|c|c|c|c|}
\hline \multirow[t]{2}{*}{ Type of $A b$ response } & \multirow[t]{2}{*}{ dpv } & \multirow[t]{2}{*}{ Serum dilution } & \multicolumn{3}{|c|}{$\mathrm{S} / \mathrm{P}$ values ${ }^{\mathrm{a}}$} & \multirow[t]{2}{*}{$h^{2}$ (SE) } \\
\hline & & & Mean & SD & CV (\%) & \\
\hline \multirow[t]{2}{*}{ Early (before booster) } & 21 & $1 / 40$ & 0.041 & 0.06 & 151 & NC \\
\hline & & $1 / 4$ & 0.403 & 0.19 & 46 & $0.57(0.15)$ \\
\hline \multirow[t]{2}{*}{ Maximum (post booster) } & 28 & $1 / 40$ & 1.349 & 0.28 & 21 & $0.46(0.11)$ \\
\hline & 35 & $1 / 40$ & 1.215 & 0.25 & 20 & $0.52(0.11)$ \\
\hline Persistence (before slaughtering) & 118 & $1 / 40$ & 0.645 & 0.30 & 46 & $0.52(0.11)$ \\
\hline
\end{tabular}

NC not calculated

${ }^{\mathrm{a}} \mathrm{Ab}$ levels are expressed relatively to a positive control (S/P values, see Methods)
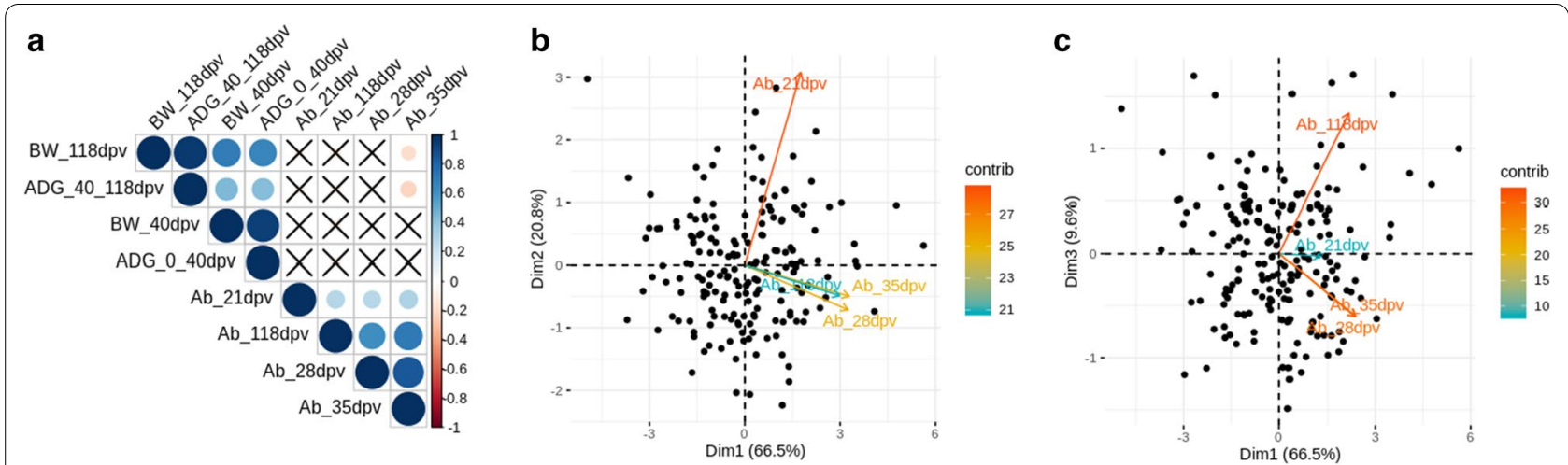

Fig. 2 Correlations of $M$. hyo Ab levels with production traits. a Correlation matrix (Pearson correlation coefficients) of $M$. hyo Ab levels in sera at 21 , 28, 35, and $118 \mathrm{dpv}$; BW at 40 and $118 \mathrm{dpv}$; and ADG from 0 to $40 \mathrm{dpv}$ and 40 to $118 \mathrm{dpv}$. Color intensity and size of the circle are proportional to the correlation coefficients. Non-significant ( $p>0.05)$ correlations are crossed out. $\mathbf{b}$, $\mathbf{c}$ Principal component analysis (PCA) of $M$. hyo Ab levels in sera at $21,28,35$, and $118 \mathrm{dpv}$ for components $\mathbf{b} 1-2$ and $\mathbf{c} 1-3$ 
distributed along the first component mostly by their $\mathrm{Ab}$ responses at 28, 35 and, $118 \mathrm{dpv}$ and along the second component by their Ab responses at $21 \mathrm{dpv}$ (Fig. 2b). The two first components explained 66.5 and $20 \%$ of the variance, respectively. The third component separated animals by their $\mathrm{Ab}$ responses at 28 or $35 \mathrm{dpv}$ vs $118 \mathrm{dpv}$ (Fig. 2c).

\section{Comparison of vaccinated and non-vaccinated groups for body weight}

We assessed the effect of vaccination on BW after 40 and $118 \mathrm{dpv}$ and on ADG during the post-weaning (0-40 $\mathrm{dpv})$ and growing (40-118 dpv) periods. We applied a mixed linear model with vaccine group (vaccinated or non-vaccinated), sex, and batch as fixed effects, age at weaning and BW at 0 or $40 \mathrm{dpv}$ as linear covariates, and litter as a random effect. Sex had a significant ( $p$-values $<0.005$ ) effect on BW at $118 \mathrm{dpv}$ and on ADG at 40-118 dpv (with higher values for males). Batch had a significant effect on BW at $40 \mathrm{dpv}$ and on ADG at $0-40$ dpv. BW at $0 \mathrm{dpv}$ had also a significant effect on all BW measurements, with a higher BW at $0 \mathrm{dpv}$ and a higher BW or ADG at older ages. Vaccination group had no significant effect on BW when the two groups of vaccinated and non-vaccinated pigs were compared (see Additional file 1: Table S5).

\section{Relationships between $M$. hyo Ab response and body weight in the vaccinated population}

To evaluate the relationships between $\mathrm{BW}$ and $M$. hyo $\mathrm{Ab}$ levels after vaccination, we performed a correlation analysis (Fig. 2a). BW measurements at different time points were positively and significantly $(p$-values $<0.05)$ correlated throughout the animals' lifetime. The ADG during the post-weaning period $(0-40 \mathrm{dpv})$ and during the growing period (40-118 dpv) were also positively correlated (Fig. 2a). As shown in Fig. 2a, Ab levels at 35 dpv and BW at $118 \mathrm{dpv}$ or ADG during the growing period (from 40 to $118 \mathrm{dpv}$ ) were slightly but significantly negatively correlated $(r=-0.18$ and- 0.22 , respectively). However, no significant correlations were found between the $\mathrm{Ab}$ levels at other time points and BW using the whole vaccinated population (Fig. 2a).

Then, we compared BW measurements between animals with high vs low or negative vs positive $\mathrm{Ab}$ response by including the corresponding vaccine group as a fixed effect in the model. Interestingly, this approach revealed that high $\mathrm{Ab}$ responders at $28 \mathrm{dpv}$ had 6.4 and $7.3 \%$ lower BW at 40 and $118 \mathrm{dpv}$, respectively, and had $9.7 \%$ and 8.3\% lower ADG from 0 to $40 \mathrm{dpv}$ and from 40 to 118 $\mathrm{dpv}$, respectively (Table $2, p<0.05$ ). In addition, animals with a positive (vs negative) Ab level at $21 \mathrm{dpv}$ had $5.3 \%$ lower BW at $40 \mathrm{dpv}$ and 8.1\% lower ADG from 0 to 40 $\operatorname{dpv}(p=0.007)$. Thus, overall, these results show a slight but significantly reduced BW and ADG for the higher $\mathrm{Ab}$ vaccine responders that could be detected as soon as 40 $\mathrm{dpv}$ and persisted until slaughter at $118 \mathrm{dpv}$.

\section{Genetics of vaccine $A b$ response}

Estimates of the heritability of $M$. hyo Ab response levels were within the same range at all time points ( 0.46 to $0.57)$, with a tendency to be slightly higher at the earliest time point (Table 1 and Additional file 1: Table S4). Estimates of heritabilities and phenotypic and genetic correlations between $\mathrm{Ab}$ responses to $M$. hyo vaccination at the different time points are summarized in Additional file 1: Table S6. Estimates of genetic correlations of $\mathrm{Ab}$ levels at $21 \mathrm{dpv}$ with $\mathrm{Ab}$ levels at the three later time points (92 to $98 \%$ ) were very high. The lowest correlations were detected between Ab levels at 28 and 35, and

Table 2 Estimates of differences in body weight (BW, $\mathbf{k g}$ ) at 40 and $118 \mathrm{dpv}$ and in average daily gain (ADG, $\mathbf{k g} / \mathrm{day}$ ) from 0 to $40 \mathrm{dpv}$ and from 40 to $118 \mathrm{dpv}$ between pigs with high vs low or positive vs negative $M$. hyo Ab response

\begin{tabular}{|c|c|c|c|c|c|}
\hline \multicolumn{2}{|c|}{$\begin{array}{l}\text { Groups of contrasted } \mathrm{Ab} \text { responses } \\
\text { to vaccination }\end{array}$} & \multirow[t]{2}{*}{ BW at $40 \mathrm{dpv}$} & \multirow[t]{2}{*}{ ADG 0-40 dpv } & \multirow[t]{2}{*}{ BW at $118 \mathrm{dpv}$} & \multirow{2}{*}{$\begin{array}{l}\text { ADG } \\
\text { at } 40-118 \\
\text { dpv }\end{array}$} \\
\hline dpv & Classification & & & & \\
\hline \multirow[t]{2}{*}{21} & High vs low & 0.102 & 0.099 & 0.088 & 0.194 \\
\hline & Positive vs negative & $0.007^{\mathrm{a}}$ & $0.007^{\mathrm{a}}$ & 0.054 & 0.191 \\
\hline 28 & High vs low & $0.025^{b}$ & $0.025^{b}$ & $0.019^{b}$ & $0.029^{b}$ \\
\hline 35 & High vs low & 0.444 & 0.443 & 0.113 & 0.128 \\
\hline \multirow[t]{2}{*}{118} & High vs low & 0.259 & 0.262 & 0.143 & 0.182 \\
\hline & Positive vs negative & 0.833 & 0.841 & 0.418 & 0.310 \\
\hline
\end{tabular}

${ }^{\text {a }}$ negative $>$ positive; ${ }^{\text {blow }}>$ high

High vs low and positive vs negative animals were defined as described in the Methods section. Details on the assignment of animals to groups at each time point are provided in Additional file 1: Table S1. BW was fitted using a linear mixed model with sex, batch and groups of contrasted responses to vaccination at each time point (high vs low or positive vs negative) as fixed effects, age at weaning and BW at $0 \mathrm{dpv}$ (weaning) as linear covariates, and litter as random effect. Classification $p$-values of the effect of contrasted groups of vaccine responders at each time point are in this table (significant $p$-values are in italics) 
Ab levels at $118 \mathrm{dpv}$ (0.66 and 0.78, respectively). Estimates of phenotypic correlations were all lower than the corresponding estimates of genetic correlations, especially for correlations of $\mathrm{Ab}$ response at $21 \mathrm{dpv}$ with later time points (see Additional file 1: Table S6).

By performing GWAS for each of the Ab phenotypes, we were able to identify two genomic regions that were associated with $M$. hyo Ab levels at $21 \mathrm{dpv}$ with sera diluted $1 / 4$ (Fig. 3 and Additional file 1: Table S7). The QTL on Sus scrofa chromosome 1 (SSC1) SSC1:261,713,894-261,843,495 (129,601 bp long) included three SNPs with FDR $<0.1$ and one SNP (AX-116155504) with FDR $=0.047$. The QTL on SSC4, between SSC4:10,201,158 and SSC4:11,076,588 (875,430 bp long), included 24 SNPs with a FDR $<0.1$ and 51 SNPs with a FDR $<0.05$, with AX-116223305 being the most strongly associated SNP $(\mathrm{FDR}=0.04)$. The annotated genes that mapped to these QTL are DAB2IP for the QTL on SSC1 and ASAP1, CYRIB, and GSDMC for the QTL on SSC4.

\section{Correlations of $M$. hyo Ab levels with co-expressed genes in pre-vaccination blood}

We performed transcription profiling in blood collected before vaccination for a subset of 82 pigs, by RNA-Seq and extracted modules of co-expressed genes using WGCNA. We identified 34 modules that included 31 to 1606 genes. Seven modules had at least one significant correlation with $M$. hyo Ab levels at 21 (two modules), 28 (two modules), 35 (three modules), and $118 \mathrm{dpv}$ (one module) (Fig. 4a, p <0.05). Only the dark magenta module was significantly correlated with $M$. hyo Ab levels at two different time points ( 21 and $118 \mathrm{dpv}$ ), the six other modules were correlated at only one time point. All significant correlations were low to moderate, with absolute values ranging from 0.23 to 0.37 . However, each of these seven modules was correlated with $M$. hyo Ab levels in the same orientation at each time point: positive correlations for purple, sky blue, and brown modules; negative correlations for dark magenta, dark turquoise, light cyan, and grey60 modules (Fig. 4a). The brown module was positively correlated with vaccine response at 21 $\mathrm{dpv}(\mathrm{r}=0.25)$, whereas the dark magenta module was negatively correlated $(\mathrm{r}=-0.27)$. Modules that were positively correlated with the $M$. hyo Ab levels at $28 \mathrm{dpv}$ were the purple $(r=0.23)$ and sky blue $(r=0.31)$ modules. The three modules that were negatively correlated with the $M$. hyo Ab levels at $35 \mathrm{dpv}$ were the dark turquoise $(r=-0.27)$, light cyan $(r=-0.37)$, and grey60 $(\mathrm{r}=-0.24)$ modules. Only the dark magenta module had a significant negative correlation with the $M$. hyo Ab levels at $118 \mathrm{dpv}(\mathrm{r}=-0.27)$.

Five of the seven WGCNA modules that were significantly correlated with Ab levels were enriched in blood transcriptomic modules (BTM) defined by $\mathrm{Li}$ et al. [38] (Fig. 4b and Additional file 1: Table S8). The dark magenta module was enriched in the BTM annotated "chromosome Y linked". The brown module was enriched in the BTM annotated for heme biosynthesis (M171 and M222), cell cycle (M4.1 and M4.2) and dendritic cell/ antigen presentation (M87). The purple module had functions enriched in BTM annotated for cell migration (M45 and M91), natural killer cell enrichment and activation (M7.2, MM61.0, M61.2, M157 and signature S1),

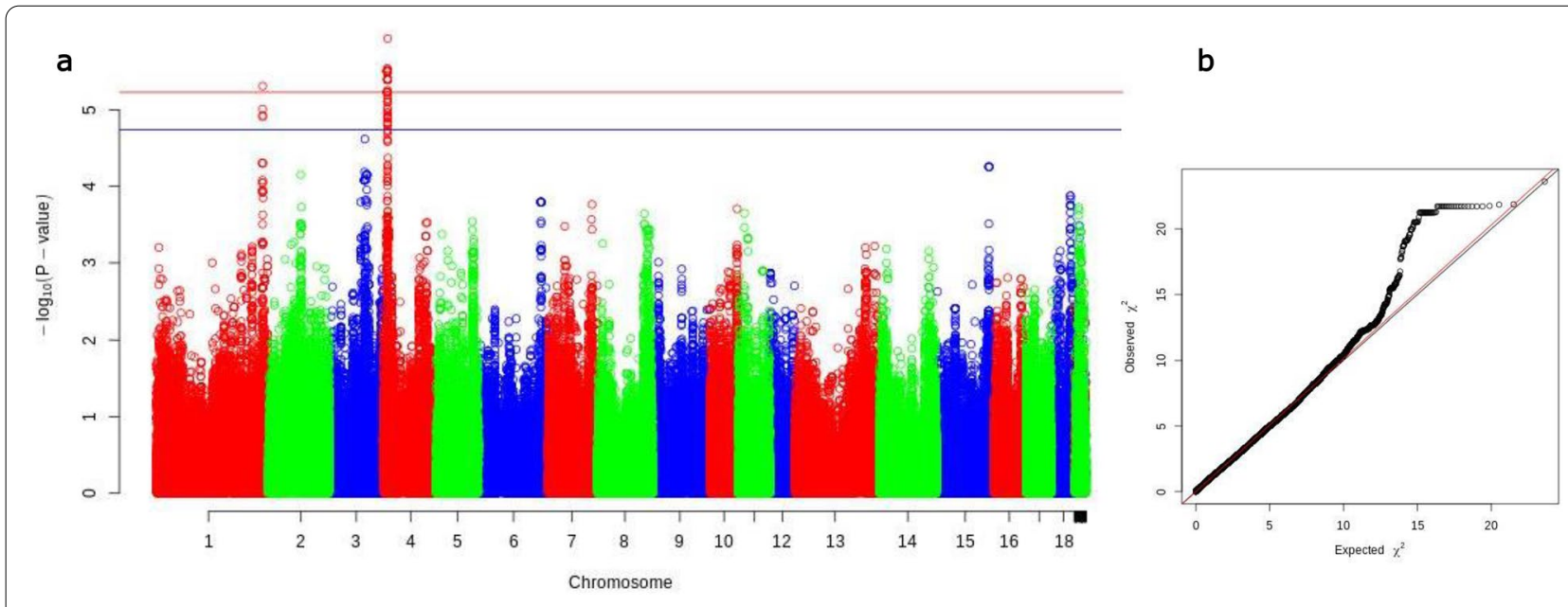

Fig. 3 Genome-wide association for M. hyo Ab levels at 21 dpv. M. hyo Ab levels were assessed in sera diluted 1/4. a Manhattan plot based on -log 10 ( $p$-value) from GWAS and imputation analysis against chromosome position annotation of the swine genome assembly 11.1 (Sscrofa11.1). The blue line indicates suggestive association threshold $(F D R=0.1)$ and the red line indicates genome-wide significant threshold $(F D R=0.05)$. $\mathbf{b} Q Q$ plot showing the expected distribution of association statistical tests (X-axis) across the SNPs compared to the observed values (Y-axis) 


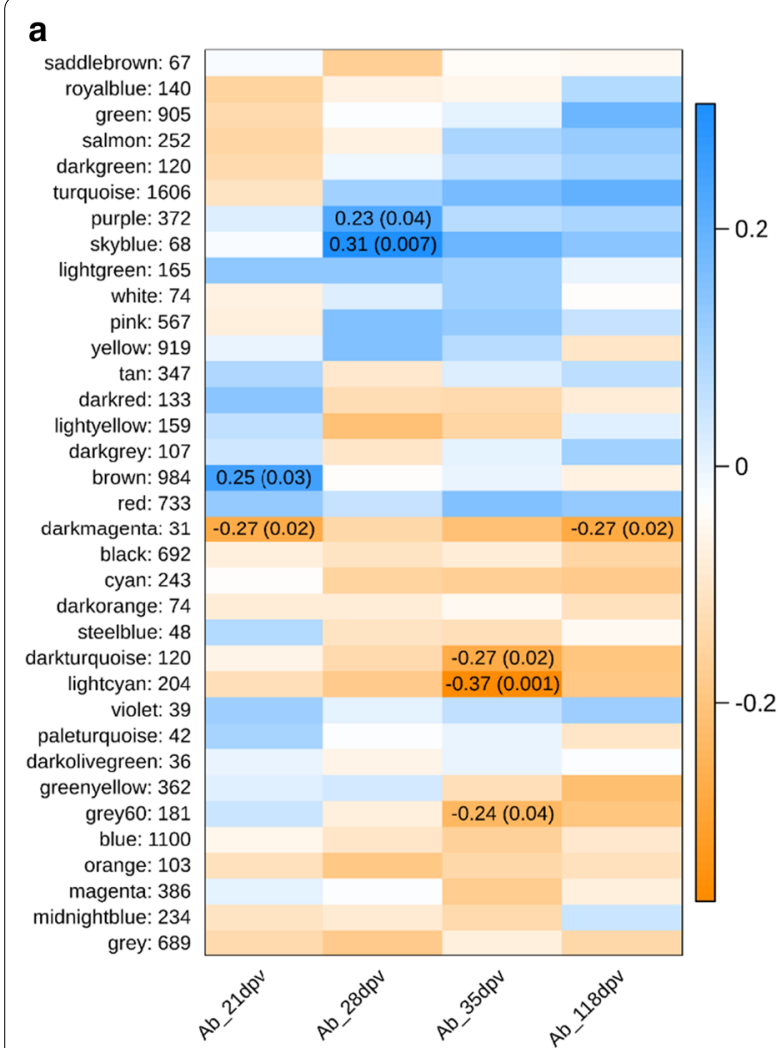

b

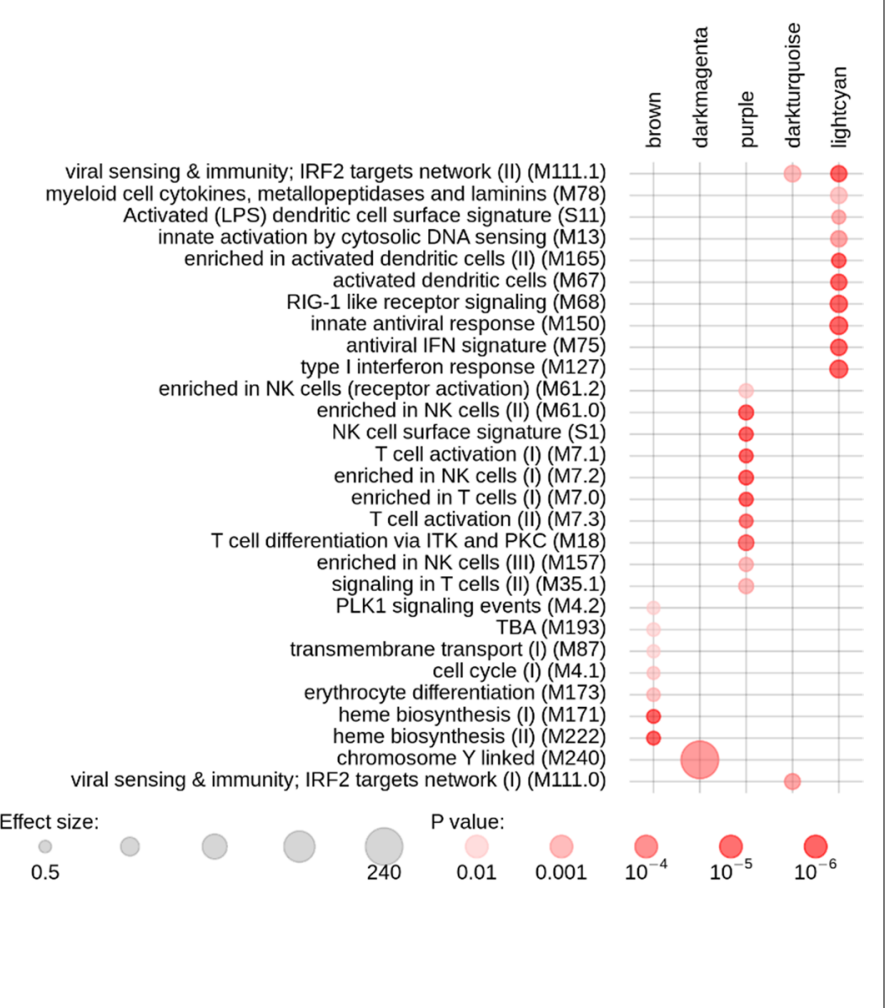

Fig. 4 Weighted gene co-expression network analysis (WGCNA) of modules and M. hyo-specific Ab response relationships. a Modules extracted by co-expression analyses in blood RNA-Seq dataset (at $0 \mathrm{dpv}$ ) are in rows labelled with a color; the number of genes contained in the given module is indicated after the color. Genes that were not assigned to a specific module $(n=689)$ are grouped in the last module labelled in grey color. The heatmaps are color-coded according to Pearson's correlation coefficient between the given module eigengene and the M. hyo Ab levels at 21, 28, 35 , and $118 \mathrm{dpv}$ (from positive in blue to negative in orange). Correlation coefficients along with their $p$-value in parenthesis are mentioned when the $p$-value $<0.05$. b Feature set enrichment analyses (FSEA) of modules correlated with M. hyo-specific Ab responses. Enrichment was calculated with hypergeometric tests for each WGCNA module (foreground set) among the total RNA-Seq gene set (background set). Only the WGCNA modules that showed a significant enrichment (hypergeometric test adjusted $p$-value $<0.01$ ) in any of the BTM were included. The strength of the $p$-value is illustrated by a gradient of red. The effect size corresponds to the enrichment calculated as $(\mathrm{b} / \mathrm{n}) /(\mathrm{B} / \mathrm{N})$ where $b$ and $\mathrm{B}$ are the numbers of genes from the given module in the $\mathrm{fg}$ and bg sets, respectively; $\mathrm{n}$ and $\mathrm{N}$, the sizes of the $\mathrm{fg}$ and bg sets, respectively. (TBA = to be annotated)

and T cell enrichment and activation (M7.0, M7.1, M7.3, M18, M35.0 and M35.1). The dark turquoise and light cyan modules had annotated functions in innate antiviral immunity (M13, M68, M75, M111.0, M111.1, M127 and M150), inflammation/immune response (M24, M37.0, M78 and M112.0), and activation of dendritic cells (MS11, M67 and M165).

\section{Identification of differentially expressed genes in blood before vaccination between pigs with divergent $\mathrm{Ab}$ responses to the $M$. hyo vaccine}

Differential expression analyses compared groups of high vs low extreme $\mathrm{Ab}$ responders at 21, 28, 35, and $118 \mathrm{dpv}$, and groups of positive vs negative Ab responders at 21 and $118 \mathrm{dpv}$. We identified four differentially expressed genes at $21 \mathrm{dpv}$ between positive and negative $\mathrm{Ab}$ responders and one differentially expressed gene at 28 dpv between high and low responders (Table 3). A set of 52 genes were differentially expressed between the two groups of responders at $118 \mathrm{dpv}$ at FDR $<0.1$, including a subset of seven genes with FDR $<0.05$.

Since the DE analyses revealed only a few DE genes, functional enrichment analysis was performed using a method that relies on the whole set of analyzed genes that are ranked based on the absolute $\operatorname{logFC}$ obtained in the DE analyses. The functions of genes that had a higher expression in the pre-vaccination blood transcriptome of the low responders at $21 \mathrm{dpv}$ were heme biosynthesis (M171) and platelet activation (M196 and M199) (Fig. 5 and Additional file 1: Table S9). Genes of the chromosome Y-linked module (M240) had a higher expression in the pre-vaccination blood transcriptome of positive responders at $21 \mathrm{dpv}$. For $\mathrm{Ab}$ responses at 28 and 35 $\mathrm{dpv}$, genes associated to the same functions had a higher 
Table 3 Differentially expressed genes in blood before vaccination between groups of animals with divergent Ab responses to $M$. hyo vaccination at different days post-vaccination (dpv)

\begin{tabular}{|c|c|c|c|c|c|}
\hline \multirow[t]{2}{*}{ Type of Ab response } & \multirow[t]{2}{*}{ dpv } & \multirow[t]{2}{*}{ Classification } & \multirow{2}{*}{$\begin{array}{l}\text { Number } \\
\text { of differentially } \\
\text { expressed genes }\end{array}$} & \multicolumn{2}{|c|}{$\begin{array}{l}\text { Differentially expressed genes with HUGO gene } \\
\text { nomenclature committee symbol }\end{array}$} \\
\hline & & & & $\begin{array}{l}\text { Higher expression in "high" } \\
\text { or "pos" }\end{array}$ & $\begin{array}{l}\text { Higher expression in "low" } \\
\text { or "neg" }\end{array}$ \\
\hline \multirow[t]{2}{*}{ Early (before booster) } & 21 & High vs low & 0 & & \\
\hline & & Negative vs positive & $4\left(4^{a}\right)$ & & $\begin{array}{l}\text { BARD1 1 }{ }^{\mathrm{a}}, \mathrm{LMBR}^{\mathrm{a}}{ }^{\mathrm{a}}, \mathrm{TMEM}^{2} 36^{\mathrm{a}} \\
\quad C C D C 158^{\mathrm{a}}\end{array}$ \\
\hline \multirow[t]{2}{*}{ Maximum (post booster) } & 28 & High vs low & $1\left(1^{\mathrm{a}}\right)$ & & $D N A H 9^{a}$ \\
\hline & 35 & High vs low & 0 & & \\
\hline \multirow[t]{2}{*}{$\begin{array}{l}\text { Persistence (before } \\
\text { slaughtering) }\end{array}$} & 118 & High vs low & $52\left(7^{\mathrm{a}}\right)$ & $\begin{array}{l}\text { TERB2 }{ }^{\mathrm{a}}, \text { SMPD2, ELOVL1, NCLN, } \\
\text { ZNF48, CLCN7, GSDMD, ULK2, } \\
\text { ZNF668, TNFRSF18, PTPN18, } \\
\text { PIM3, MARVELD1, PHB, ETNK2, } \\
\text { HIST1H4H, ZNF787 }\end{array}$ & $\begin{array}{l}\text { TMTC }^{\mathrm{a}}, \text { ICE2 } \\
\text { L }, \text { NABP 2, CCNC, } \\
\text { LRIF , AHI1, RPAP3, STK39, } \\
\text { ABRAXAS1, FAM214A, } \\
\text { TRAM1, ZNF280D, AEBP2, } \\
\text { ZNF350, TAOK1 }\end{array}$ \\
\hline & & Negative vs positive & 0 & & \\
\hline
\end{tabular}

${ }^{\mathrm{a} F D R}<0.05$

expression in the pre-vaccination blood transcriptome of high responders at both time points. The functions were mainly related to innate antiviral immunity (M13, M68, M75, M111.1, M127, and M150) and to dendritic cells (M67). For the $\mathrm{Ab}$ response at $118 \mathrm{dpv}$, the genes with a higher expression in the pre-vaccination blood transcriptome of the positive responders were annotated to modules related to cell junction and adhesion (M1.0, M1.1, and M51), extracellular matrix (M2.0, M2.1 and M2.2), platelet activation (M85), axon guidance (M110), signal transduction and inflammation (M0 and M82) and myeloid cells (M4.3).

Blood biomarkers to predict $A b$ response to $M$. hyo vaccine We applied the sPLS-DA method [53] to select predictive genes that can help classify animals as high vs low Ab responders (at 21, 28, 35, and $118 \mathrm{dpv}$ ) or positive vs negative $\mathrm{Ab}$ responders (at 21 and $118 \mathrm{dpv}$ ) (see Additional file 1: Table S10). The detailed contributions of each gene are in Additional file 1: Table S11. Interestingly, the SH3RF1 gene was a predictor of extreme $\mathrm{Ab}$ responders at both 35 and $118 \mathrm{dpv}$. We defined a set of 101 candidate predictive genes by grouping the genes identified for each time point. PLS-DA were run with the 101-gene set to assess its prediction capacity for classifying animals as high vs low or positive vs negative $\mathrm{Ab}$ responders at all time points (Fig. 6 and Additional file 1: Table S11). A good prediction was obtained with the first component (area under the curve $(\mathrm{AUC})>0.86$ ) and a nearly perfect prediction with two or three components (AUC > 0.99), with significant balanced error rates (BER) for $\mathrm{Ab}$ responses at all time points (BER ranging from 0.10 to 0.38 ). Interestingly, among this set of genes, six were in the DE gene list: NCLN, ENSSSCG00000032640, CCDC158, TMEM236, DNAH9 and BARD1. In addition, 10 of these predictive genes have been reported to be under genetic control in an expression GWAS analysis performed on 60-day old pig blood transcriptome [54]: TXLNB, PPP6R3, ALMS1, PAFAH2, SLC39A7, CCDC158, MASTL, DNAH9, SENP7, and TBC1D12.

\section{Discussion}

In this study, we characterized the variability of vaccine humoral response to $M$. hyo in pigs. We identified genetic information and pre-vaccination baseline transcriptomic signatures that could predispose to and predict individual $M$. hyo Ab levels induced after vaccination and monitored at different time points: early response after the first injection ( $21 \mathrm{dpv})$, maximum intensity response after the booster ( 28 and $35 \mathrm{dpv}$ ), and persistence of $\mathrm{Ab}$ response until slaughter (118 dpv).

The mechanisms of the vaccine-induced protection to control $M$. hyo infection in pigs are not yet fully understood. The $M$. hyo vaccine is known to induce both local and systemic immune responses that involve specific $\mathrm{Ab}$ production and cellular immunity [5, 55-57]. However, the respective roles of these components of the host immune response on the vaccine-induced protection have not yet been determined and no direct correlation has been reported between the variability of any vaccine response parameter and the protection efficiency after $M$. hyo challenge $[5,55,56]$. Vaccine formulations, routes of administrations, or adjuvants differed between these studies and the number of animals studied were relatively small (less than 10). Studies that include animal challenge with the vaccine pathogen after vaccination on 
platelet activation - actin binding (M196) heme biosynthesis (I) (M171) chromosome $Y$ linked (M240) transmembrane transport (I) (M87) innate antiviral response (M150) adhesion and migration, chemotaxis (M91) activated dendritic cells (M67) antiviral IFN signature (M75)

RIG-1 like receptor signaling (M68) type I interferon response (M127) integrin cell surface interactions (II) (M1.1) innate activation by cytosolic DNA sensing (M13) viral sensing \& immunity; IRF2 targets network (II) (M111.1) extracellular matrix (II) (M2.1) platelet activation \& blood coagulation (M199) enriched in NK cells (I) (M7.2) extracellular matrix (I) (M2.0)

integrin cell surface interactions (I) (M1.0) extracellular matrix (III) (M2.2) TBA (M116) cell adhesion (M51) chemokine cluster (I) (M27.0) axon guidance (M110)

platelet activation and degranulation (M85) targets of FOSL1/2 (MO)

muscle contraction, SRF targets (M195) signal transduction, plasma membrane (M82) myeloid cell enriched receptors and transporters (M4.3)
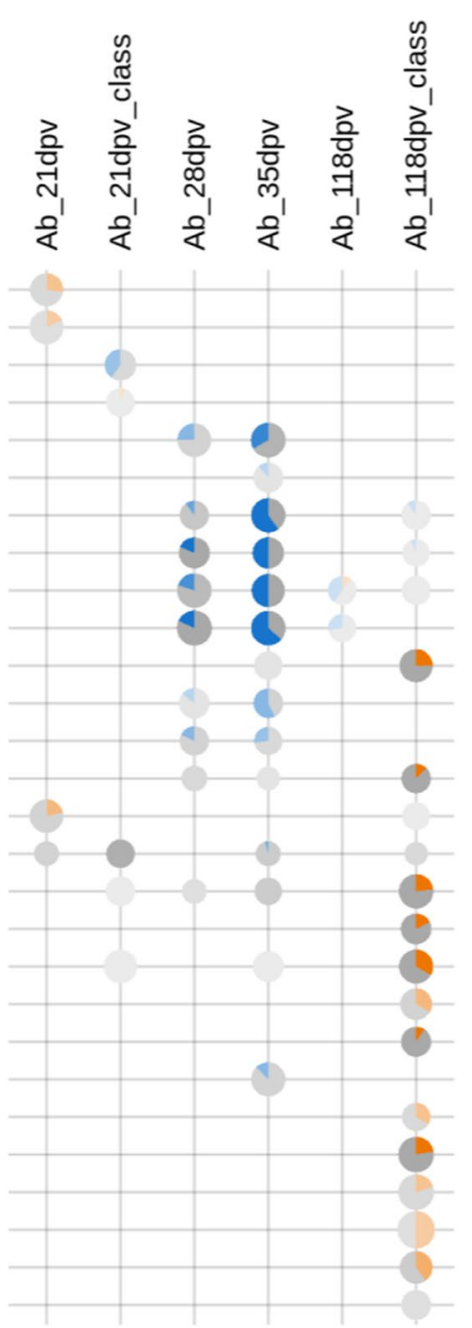

Effect size:

0.5

$P$ value:

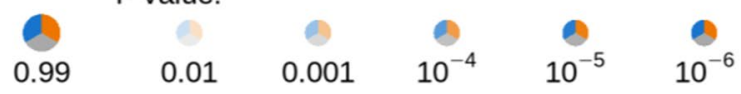

Fig. 5 Feature set enrichment analyses (FSEA) of differentially expressed (DE) genes between animals with divergent Ab responses to M. hyo vaccination. The CERNO test was operated on lists of genes that were ranked by their absolute log FC of the DE analyses that compare groups of contrasted responders to vaccination at $21,28,35$, and $118 \mathrm{dpv}$ (high vs low or positive vs negative). BTM significantly enriched in each list $(p<0.01$ and AUC $>0.75)$ are represented in rows. BTM are named by their title and ID in parenthesis. The strength of the $p$-value is illustrated by the transparency of color; the effect size (AUC) is illustrated with the plot size. Significantly $(p<0.05)$ up-regulated genes in high or positive responders are colored in blue and downregulated genes are colored in orange; the others are in grey. (TBA $=$ to be annotated)

larger populations are needed to establish the correlates of vaccination protection. In our study, we focused on the humoral response following vaccination and found a high inter-individual variability in $M$. hyo Ab levels, influenced by both the host genetics and blood transcriptomics. Thus, we provide a proof of concept that genetic and blood transcriptomic data collected before vaccination are relevant resources to predict vaccine $\mathrm{Ab}$ response levels, which could be applied to the correlates of protection that need to be established in future studies.
Ab response levels within an animal were positively correlated with each other across time points, which revealed the absence of an antagonism between $\mathrm{Ab}$ response levels at different time points. Selecting for $\mathrm{Ab}$ response intensity to vaccination may have an impact on pig production performance due to tradeoff issues. Comparisons between vaccinated and nonvaccinated animal groups showed no differences in BW, which highlights that the vaccine has no negative effect on BW at the whole population level. In field 

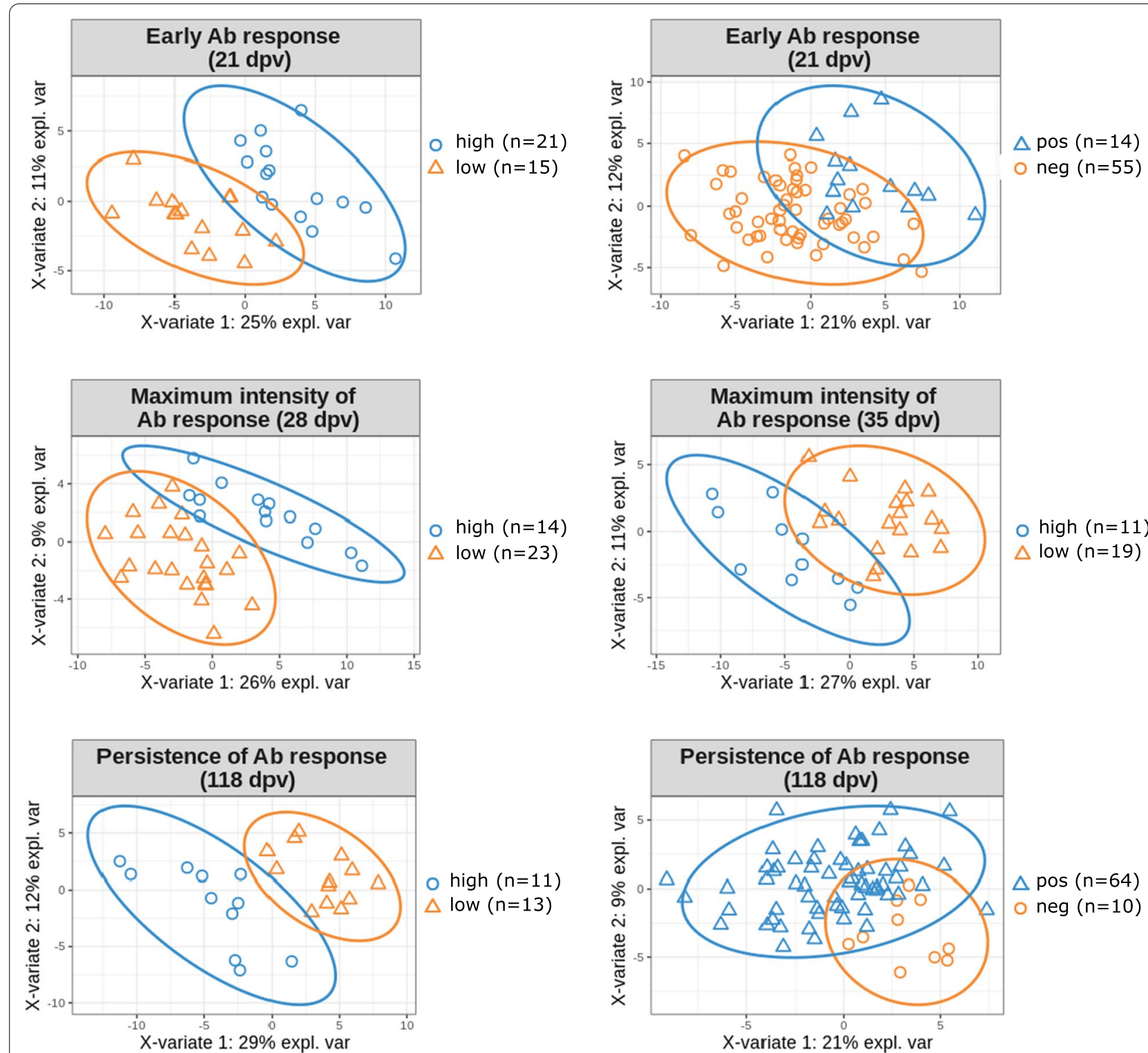

Fig. 6 Partial least square-discriminant analysis (PLS-DA) with the 101 predictive genes for M. hyo vaccine response. Projection of the groups of contrasted responders to vaccination at 21,28,35, and $118 \mathrm{dpv}$ (high vs low or positive vs negative) into the subspace spanned by the first two components after a PLS-DA analysis with the 101 candidate predictive genes. Confidence ellipses for each class are plotted (confidence level set to 95\%)

conditions where $M$. hyo is circulating, vaccinated pigs have higher growth rates $[5,6]$, due to the herd protection against the pathogen. In our study, in which no $M$. hyo infection occurred, we observed negative correlations between $\mathrm{Ab}$ responses to $M$. hyo vaccination and BW. The high vaccine responders had significantly lower BW and ADG values than the low $\mathrm{Ab}$ responders, which suggests a trade-off. Thus, breeding goals should aim at reaching levels of $\mathrm{Ab}$ that are sufficient for an efficient protection of animals that persists throughout life, rather than selecting for maximal $\mathrm{Ab}$ response capacity. Correlates of protection are still lacking to be able to determine what threshold of $\mathrm{Ab}$ level would be sufficient to optimize protection while limiting the decrease in BW. When vaccine response traits are included in breeding programs, a joint assessment of functional trade-offs and economic impacts will be necessary to optimize both vaccine effectiveness and production traits. The balance between sustainability, feasibility and desirability of breeding livestock for 
disease resistance remains a main issue that needs to be addressed [58].

From the blood transcriptome profiles obtained prior vaccination, we identified differentially expressed genes in animals that showed divergent levels of Ab response to vaccination, especially for persistence of the $\mathrm{Ab}$ response. Although these genes were not shared with previously reported gene signatures associated with early response to vaccination in humans or pigs $[35,37,42]$, they were enriched in blood cell functions that are biologically relevant to inter-individual variability of $\mathrm{Ab}$ response to vaccination. The inflammation, innate antiviral immunity, platelet activation, dendritic cells/antigen presentation, myeloid cells, natural killer cells, and $\mathrm{T}$ cell activation functions associated with the $\mathrm{Ab}$ response that we have identified in our study have already been reported as gene signatures of vaccination in humans $[38,59]$, pigs [43], and sheep [39, 40].

The pre-vaccination blood transcriptome predicted $M$. hyo $\mathrm{Ab}$ levels at the early and maximum intensity responses, and strikingly at a late time point that corresponded to $\mathrm{Ab}$ persistence. Interestingly, the blood cell functions involved in predisposition to vaccination response varied between time points, which suggests that the underlying biological mechanisms involved in the prediction probably differ, and their study needs to be deepened. A high early response was associated with a lower expression in blood of genes that are related to cell cycle and transcription, heme biosynthesis, and platelet activation functions. High responders at the maximum intensity of $\mathrm{Ab}$ response showed a higher expression of genes related to dendritic cell, natural killer and $\mathrm{T}$ cell activation and antiviral and innate immune response (mainly interferon signature and RIG-1 like sensing), as well as complement activation. The persistence of the $\mathrm{Ab}$ response was associated with genes related to cell adhesion, extracellular matrix, platelet activation and monocyte signature. Finally, high $\mathrm{Ab}$ responses at nearly all time points were associated with a decreased representation of genes associated to the chromosome Y-specific module (M240) compared to low Ab responses. All these blood cell functions have physiological roles that support their implication in the immune capacity of animals to mount an $\mathrm{Ab}$ response to vaccination. The pig Y chromosome harbors genes with regulatory properties that may shape the immune cell transcriptomes [60]. Heme regulates B-cell differentiation and antibody class switch [61, 62] and, in general, an altered CD4 T cell signature can be used as a predictive immune phenotype for low vaccine responsiveness in middle-aged humans [63].

A previous study in pigs did not identify any biomarkers in the blood transcriptome before vaccination for the prediction of $M$. hyo Ab levels measured 10 days after a booster vaccination [42]. It should be noted that, in the same population, the kinome (global cellular kinase activity) revealed prior vaccination candidate biomarkers [32]. In our study, we investigated the early, maximum intensity, and persistence of $\mathrm{Ab}$ responses and searched for predictors of the intensity of vaccine response by studying genes that are expressed in pre-vaccination blood. Merging the best predictors of $\mathrm{Ab}$ responses at each time point led to a set of 101 genes (see Additional file 1: Table S11) that had an enhanced performance of prediction at all time points compared to single subsets of genes defined at each time point. A sPLS-DA analysis does not necessarily select genes that are of biological relevance to the predicted phenotype. However, six of the 57 genes that were differentially expressed between the high and low responders were found in this set of 101 genes that were predictive of $\mathrm{Ab}$ responses. These six genes (NCLN, ENSSSCG00000032640, CCDC158, TMEM236, DNAH9, and $B A R D 1$ ) were among the best contributors to the prediction. More studies are needed to refine the list of candidate predictors and to validate them in other populations, with different genetic setups and environments of production. Since more and more studies aim at identifying genetic predictors and, more generally, biomarkers of vaccine effectiveness in pigs, it will be essential to analyze whether such predictors apply to different vaccines. Integrating various layers of biological information from the host (genetics, transcripomics, kinomics, etc.) and its gut microbiota is expected to create a breakthrough in our understanding of the determinants of vaccine effectiveness and more globally on immune capacity and animal robustness, with potential applications to improve the sustainability of pig production systems.

In this study, an inter-individual variability of $\mathrm{Ab}$ levels in response to $M$. hyo vaccination was reported, with females exhibiting higher levels of $\mathrm{Ab}$ than males (uncastrated) at the latest time point. This is consistent with the correlation that we found between a male-specific module (M240) and Ab response that was previously reported in humans for other vaccines [38], and highlights a gender bias in $\mathrm{Ab}$ production. Sex differences have been described in immunity to multiple vaccines, including both inactivated and live vaccines in humans, with $\mathrm{Ab}$ responses often being higher in females than in males $[64,65]$. Thus, sex differences in immune responses to vaccines that could be caused by genetic, hormonal, microbiota, and environmental factors, or a combination of these, should be taken into account in vaccination studies.

In humans, estimates of heritability of $\mathrm{Ab}$ responses to several vaccinations ranged from low $(<0.20)$ to high $(>0.80)$, depending on the vaccine [23, 66-69]. In pigs, mainly low to moderate heritabilities of specific $\mathrm{Ab}$ 
production have been reported $[29,30]$. In a previous study on Large White pigs, we showed that $M$. hyo-specific $\mathrm{Ab}$ response after a one-shot injection of vaccine had a large phenotypic variance, with a low heritability of 0.12 [31]. Here, we found heritabilities of $M$. hyo-specific $\mathrm{Ab}$ levels ranging from 0.46 to 0.57 , with the higher value for the early M. hyo Ab levels at $21 \mathrm{dpv}$. These heritability values might be slightly overestimated, as common environmental effect of birth litter was not included in the final model of analysis due to numerical issues. However, the variance due to common litter effects rarely exceeds $10 \%$ of the phenotypic variance, so that heritability values of 0.46 to 0.57 are very likely to be mainly due to additive genetic variation. GWAS revealed two significant peaks for early M. hyo Ab levels at $21 \mathrm{dpv}$, but no associations at other time points. Thus, we confirm the influence of the host genetics on vaccine effectiveness but larger population sizes are needed to go deeper in the analysis of the underlying genetic determinisms, which likely involves numerous genetic loci spread along the genome. In addition, we anticipate that biological relays that are controlled by different genetic determinisms are put in place during the time course of the vaccine response.

The few genes that map to the two GWAS peaks have functional links with immunity in humans. On SSC1, the $D A B 2 I P$ gene encodes the DAB2 interacting protein that functions as a scaffold protein involved in numerous processes including innate immune response, inflammation and cell cycle. A GWAS in humans revealed associations of this gene with aggressive prostate cancer, $D A B 2 I P$ being a candidate tumor suppressor gene [70]. DAB2IP is also known to inhibit tumor cell growth in vitro and in vivo, which highlights important properties for anticancer therapies [71]. On SSC4, the ASAP1 gene (ArfGAP with SH3 domain, ankyrin repeat and $P H$ domain 1) encodes an ADP-ribosylation factor GTPase-activating protein. ASAP1 plays a role in regulating the migration of dendritic cells, with a possible impact on predisposition to tuberculosis [72]. Associations of this gene with mean platelet volume and platelet counts have also been reported [73, 74]. The CYRIB gene (CYFIP related Rac1 interactor $B$ ) is related with several pathways, among which response to an elevated concentration of platelet cytosolic $\mathrm{Ca} 2+$. GWAS in humans have revealed associations of variants of regulatory elements of CYRIB with lymphocyte counts [75]. The GSDMC gene (gasdermin C) was initially identified as a gene that is preferentially expressed in metastatic melanoma cells [76] and also in the epithelium of the skin and gastrointestinal tract [77], while GWAS in humans revealed associations of variants in GSDMC with monocyte counts [78].

Finally, an eGWAS performed on 60-day old pig blood transcriptome revealed that 10 of the 101 genes that were predictive of $\mathrm{Ab}$ responses in our study are under genetic control [54]. Deciphering the genetic control of the expression of genes in blood should also help identify the best variant predictors of vaccine responses that could be implemented in breeding programs. Of note, we also recently reported an impact of the fecal microbiota collected before vaccination on vaccine effectiveness in the same population [79], in agreement with findings on another pig population [42]. The accumulation of data on genetic variability and predictors to vaccine responses (transcriptome, kinome, microbiome) should provide new insights to improve vaccination efficacy. From a One-Health perspective, precision livestock production and personalized medicine share the same requirements to better understand the determinants of individual baseline variability that shape immune competence, and to assess if such knowledge will be useful in future breeding practices.

\section{Conclusions}

We showed and thus confirmed a genetic basis for the variability of $\mathrm{Ab}$ vaccine response in pigs vaccinated against M. Hyo. Heritability of the Ab response at all time points could be estimated and genomic regions associated with the early response $(21 \mathrm{dpv})$ identified. We also identified individual baseline blood transcriptomic signatures prior to vaccination that predicted high or low responses in the tested population. Similar genetic and genomic studies could be applied to the correlates of protection that still need to be established. These results highlight that the variability of baseline genomic expression beyond SNPs may be relevant to predict the variability of vaccine effectiveness and baseline immune competence.

\section{Supplementary Information}

The online version contains supplementary material available at https://doi. org/10.1186/s12711-021-00614-5.

Additional file 1: Table S1. Individual data and metadata. Table S2. Descriptive statistics of the groups of animals with contrasted Ab response to vaccination against $M$. hyo at different days post-vaccination (dpv) within the total population and the subset for which RNASeq data are available. Table S3. Effects of sex, batch, age at weaning and litter on M. hyo Ab levels. Table S4. Correlations of Ab responses to M. hyo vaccination at different days post-vaccination (dpv). Table S5. Effects of sex, batch, age at weaning, BW at $0 \mathrm{dpv}$, vaccination and litter on BW at 40 and $118 \mathrm{dpv}$ and ADG from 0 to 40 and 40 to $118 \mathrm{dpv}$. Table S6. Genetic parameters of $A b$ responses to $M$. hyo vaccination at different days post-vaccination (dpv). Table S7. Suggestive (FDR $<0.1)$ and significant (FDR < 0.05) SNPs associated with the early M. hyo Ab levels at $21 \mathrm{dpv}$ (sera diluted 1/4). Table S8. FSEA of transcript overlap between WGCNA modules and BTM. Table S9. FSEA of differentially expressed genes between groups of animals with contrasted $A b$ responses to $M$. hyo vaccination. Table S10. Determination of the number of genes (maximum 25) necessary to reach an optimized prediction of extreme $A b$ responders to $M$. hyo vaccination by sPLS-DA. Table S11. Contribution to the sPLS-DA analysis 
of the different phenotypes of the set of 101 genes predictive of extreme $A b$ responders to $M$. hyo vaccination. Table S12. PLS-DA with the set of 101 genes predictive of extreme $A b$ responders to M. hyo vaccination.

\section{Acknowledgements}

The authors would like to thank Isabelle Schwartz-Cornil who coordinated the H2020 SAPHIR project that gathered a large multidisciplinary consortium and gave us an opportunity to design ad hoc experiments to study individual variability of vaccine responses. We have special warm thanks to Chiara Ferrandi $(\dagger)$ and Alessandra Stella who helped producing the libraries for RNA-Seq at Parco Technologico (PTP, Lodi, Italy). We also thank Rémy-Félix Serre (INRAE, Get-Plage platform) for his contribution to the RNA-Seq library sequencing. We thank the INRAE Gentyane Genomic Services platform (Clermont-Ferrand, France) who performed the animal SNP genotyping. We are grateful to Hélène Hayes (INRAE GABl unit) for a much appreciated proofreading of the manuscript. We thank all members of the Genetics, Microbiota, Health team of the INRAE GABI unit for their help at all steps of the project, including animal sampling. We thank Andrea Rau and Florence Jaffrezic (INRAE GABI unit) for their helpful advice on statistical analyses. We also thank the pig team of the GenESI unit for animal housing and sampling all along the experiment.

\section{Authors' contributions}

$F B, J E, M H P v d L$ and CRG conceived and designed the experimental design; $Y B$ and LR were in charge of the pig production in the experimental farm; JJL and GL managed animal sampling; GL organized the biobanking of all samples; $O B$ produced the RNA sequencing data; $F B$ characterized the vaccine response; JE and TM performed bioinformatics analyses with the help of BBH; FB, JE and MR performed GWAS analyses with the help of $\mathrm{BBH}$; JPB performed heritability analyses; FB and JE performed bio-statistical analyses; CRG supervised the project; FB and CRG interpreted all data and wrote the paper. All authors read and approved the final manuscript.

\section{Funding}

This project has received funding from the European Union's Horizon 2020 Programme for research, technological development and demonstration under the Grant Agreement n'633184. This publication reflects the views only of the authors, and not the European Commission (EC). The EC is not liable for any use that may be made of the information contained herein.

\section{Availability of data and materials}

The blood transcriptome RNA-Seq datasets generated and analysed during the current study are available in the SRA repository with accession number PRJNA661433. All other data generated or analysed during this study are included in this published article and its additional files.

\section{Ethics approval and consent to participate}

All animal procedures were performed according to the guidelines for the care and use of experimental animals established by INRAE (ability for animal experimentation to C. Rogel-Gaillard: A78-172; agreement for experimentation of Centre de recherche INRA Poitou-Charentes-Site expérimental du Magneraud: A17661; protocol approved by the French Ministry of Research with authorization ID APAFIS\#4295-2016022615583351 v4 after the review of ethics committee №084).

\section{Consent for publication}

Not applicable.

\section{Competing interests}

The authors declare that they have no competing interests.

\section{Author details}

${ }^{1}$ Université Paris-Saclay, INRAE, AgroParisTech, GABI, 78350 Jouy-en-Josas, France. ${ }^{2}$ INRAE, GenESI, 17700 Surgères, France. ${ }^{3}$ INRAE, GeT-PlaGe, Genotoul, 31326 Castanet-Tolosan, France.

Received: 6 August 2020 Accepted: 16 February 2021 Published online: 18 March 2021

\section{References}

1. Posteraro B, Pastorino R, Di Giannantonio P, lanuale C, Amore R, Ricciardi $W$, et al. The link between genetic variation and variability in vaccine responses: systematic review and meta-analyses. Vaccine. 2014;32:1661-9.

2. Jorge $S$, Dellagostin OA. The development of veterinary vaccines: a review of traditional methods and modern biotechnology approaches. Biotechnol Res Innov. 2017;1:6-13.

3. Maes D, Sibila M, Kuhnert P, Segalés J, Haesebrouck F, Pieters M. Update on Mycoplasma hyopneumoniae infections in pigs: knowledge gaps for improved disease control. Transbound Emerg Dis. 2018;65:110-24.

4. Holst S, Yeske P, Pieters M. Elimination of Mycoplasma hyopneumoniae from breed-to-wean farms: a review of current protocols with emphasis on herd closure and medication. J Swine Health Prod. 2015;23:321-30.

5. Maes D, Deluyker H, Verdonck M, Castryck F, Miry C, Vrijens B, et al. Effect of vaccination against Mycoplasma hyopneumoniae in pig herds with an all-in/all-out production system. Vaccine. 1999;17:1024-34.

6. Siugzdaite J, Garlaite K, Urbsiene D. Evaluation of antibody formation, daily weight gain and meat quality after vaccination of piglets. Acta Vet Hung. 2003;51:273-81.

7. Meyns T, Dewulf J, de Kruif A, Calus D, Haesebrouck F, Maes D. Comparison of transmission of Mycoplasma hyopneumoniae in vaccinated and non-vaccinated populations. Vaccine. 2006;24:7081-6.

8. Sibila M, Nofrarias N, Lopez-Soria S, Segalés J, Valero O, Espinal A, et al. Chronological study of Mycoplasma hyopneumoniae infection, seroconversion and associated lung lesions in vaccinated and non-vaccinated pigs. Vet Microbiol. 2007;122:97-107.

9. Villarreal I, Meyns T, Dewulf J, Vranckx K, Calus D, Pasmans F, et al. The effect of vaccination on the transmission of Mycoplasma hyopneumoniae in pigs under field conditions. Vet J. 2011;188:48-52.

10. Poland GA, Kennedy RB, Mckinney BA, Ovsyannikova IG, Lambert ND, Jacobson RM, et al. Vaccinomics, adversomics, and the immune response network theory: Individualized vaccinology in the 21 st century. Semin Immunol. 2013;25:89-103.

11. Raeven RHM, van Riet E, Meiring HD, Metz B, Kersten GFA. Systems vaccinology and big data in the vaccine development chain. Immunology. 2018;156:33-46.

12. Lambert ND, Haralambieva IH, Kennedy RB, Ovsyannikova IG, Pankratz VS, Poland GA. Polymorphisms in HLA-DPB1 are associated with differences in Rubella virus-specific humoral immunity after vaccination. J Infect Dis. 2015;211:898-905.

13. Kennedy RB, Ovsyannikova IG, Haralambieva IH, Lambert ND, Pankratz VS, Poland GA. Genome-wide SNP associations with Rubella-specific cytokine responses in measles-mumps-rubella vaccine recipients. Immunogenetics. 2014;66:493-9.

14. Voigt EA, Haralambieva IH, Larrabee BL, Kennedy RB, Ovsyannikova IG, Schaid DJ, et al. Polymorphisms in the Wilms tumor gene are associated with interindividual variations in Rubella virus-specific cellular immunity after measles-mumps-rubella II vaccination. J Infect Dis. 2018;217:560-6.

15. Haralambieva IH, Kennedy RB, Ovsyannikova IG, Whitaker JA, Poland GA. Variability in humoral immunity to measles vaccine: New developments. Trends Mol Med. 2015;21:789-801.

16. Scepanovic P, Alanio C, Hammer C, Hodel F, Bergstedt J, Patin E, et al. Human genetic variants and age are the strongest predictors of humoral immune responses to common pathogens and vaccines. Genome Med. 2018; 10:59

17. Wu T, Chen C, Lai S, Lin HH, Chu C, Wang L. SNP rs7770370 in HLA-DPB1 loci as a major genetic determinant of response to booster hepatitis $B$ vaccination: results of a genome-wide association study. J Gastroenterol Hepatol. 2015;30:891-9.

18. Chung S, Roh EY, Park B, Lee Y, Shin S, Yoon JH, et al. GWAS identifying HLA-DPB1 gene variants associated with responsiveness to hepatitis $B$ virus vaccination in Koreans: Independent association of HLA-DPB1*04:02 possessing rs1042169 G-rs9277355 C-rs9277356 A. J Viral Hepat. 2019;26:1318-29.

19. Pan L, Zhang L, Zhang W, Wu X, Li Y, Yan B, et al. A genome-wide association study identifies polymorphisms in the HLA-DR region associated with non-response to hepatitis B vaccination in Chinese Han populations. Hum Mol Genet. 2014;23:2210-9.

20. Linnik JE, Egli A. Impact of host genetic polymorphisms on vaccine induced antibody response. Hum Vaccin Immunother. 2016;12:907-15. 
21. Ovsyannikova IG, Kennedy RB, O’Byrne M, Jacobson RM, Pankratz VS, Poland GA. Genome-wide association study of antibody response to smallpox vaccine. Vaccine. 2012;30:4182-9.

22. Pajewski NM, Shrestha S, Quinn CP, Parker SD, Wiener H, Aissani B, et al. A genome-wide association study of host genetic determinants of the antibody response to anthrax vaccine adsorbed. Vaccine. 2012;30:4778-84.

23. O'Connor D, Png E, Khor CC, Snape MD, Hill AVS, van der Klis F, et al. Common genetic variations associated with the persistence of immunity following childhood immunization. Cell Rep. 2019;27:e4.

24. Leach RJ, Neill RGO, Fitzpatrick JL, Williams JL, Glass EJ. Quantitative trait loci associated with the immune response to a bovine respiratory syncytial virus vaccine. PLoS One. 2012;7:e33526.

25. Luo C, Qu H, Ma J, Wang J, Li C, Yang C, et al. Genome-wide association study of antibody response to Newcastle disease virus in chicken. BMC Genomics. 2013;14:42.

26. Rothschild M, Hill H, Christian L, Warner C. Genetic differences in serumneutralization titers of pigs after vaccination with pseudorabies modified live-virus vaccine. Am J Vet Res. 1984;45:1216-8.

27. Zanella R, Gava D, de Oliveira J, Schaefer R, Ciacci-Zanella JR, Biondo $\mathrm{N}$, et al. Unravelling the genetic components involved in the immune response of pigs vaccinated against influenza virus. Virus Res. 2015:210:327-36

28. Dunkelberger JR, Serão NVL, Weng Z, Waide EH, Niederwerder MC, Kerrigan MA, et al. Genomic regions associated with host response to porcine reproductive and respiratory syndrome vaccination and co-infection in nursery pigs. BMC Genomics. 2017;18:865.

29. Uddin MJ, Grosse-Brinkhaus C, Cinar MU, Jonas E, Tesfaye D, Tholen E, et al. Mapping of quantitative trait loci for mycoplasma and tetanus antibodies and interferon-gamma in a porcine $F_{2}$ Duroc $\times$ Pietrain resource population. Mamm Genome. 2010;21:409-18.

30. Edfors-Lilja I, Wattrang E, Marklund L, Moller M, Andersson-Eklund L, Andersson L, et al. Mapping quantitative trait loci for immune capacity in the pig. J Immunol. 1998;161:829-35.

31. Flori L, Gao Y, Laloë D, Lemonnier G, Leplat J, Teillaud A, et al. Immunity traits in pigs: substantial genetic variation and limited covariation. PLOS One. 2011;6:e22717.

32. Lipsit SWL, Wilkinson J, Scruten E, Facciuolo A, Denomy C, Griebel PJ, et al. Kinome profiling of peripheral blood mononuclear cells collected prior to vaccination reveals biomarkers and potential mechanisms of vaccine unresponsiveness in pigs. Sci Rep. 2020;10:11546.

33. Chaussabel D, Pascual V, Banchereau J. Assessing the human immune system through blood transcriptomics. BMC Biol. 2010;8:84.

34. Mach N, Gao Y, Lemonnier G, Lecardonnel J, Oswald IP, Estellé J, et al. The peripheral blood transcriptome reflects variations in immunity traits in swine: Towards the identification of biomarkers. BMC Genomics. 2013:14:894.

35. Gonçalves E, Bonduelle O, Soria A, Loulergue P, Rousseau A, Cachanado $M$, et al. Innate gene signature distinguishes humoral versus cytotoxic responses to influenza vaccination. J Clin Invest. 2019;129:1960-71.

36. Querec TD, Akondy RS, Lee EK, Cao W, Nakaya HI, Teuwen D, et al. Systems biology approach predicts immunogenicity of the yellow fever vaccine in humans. Nat Immunol. 2009;10:116-25.

37. Ovsyannikova IG, Salk HM, Kennedy RB, Haralambieva IH, Zimmermann MT, Grill DE, et al. Gene signatures associated with adaptive humoral immunity following seasonal influenza A/H1N1 vaccination. Genes Immun. 2016;17:371-9.

38. Li S, Rouphael N, Duraisingham S, Romero-Steiner S, Presnell S, Davis C, et al. Molecular signatures of antibody responses derived from a systems biology study of five human vaccines. Nat Immunol. 2014;15:195-204.

39. Jouneau L, Lefebvre DJ, Costa F, Romey A, Blaise-Boisseau S, Relmy A, et al. The antibody response induced FMDV vaccines in sheep correlates with early transcriptomic responses in blood. NPJ Vaccines. 2020;5:1.

40. Braun RO, Brunner L, Wyler K, Auray G, García-Nicolás O, Python S, et al. System immunology-based identification of blood transcriptional modules correlating to antibody responses in sheep. NPJ Vaccines. 2018;3:41.

41. Adler M, Murani E, Ponsuksili S, Wimmers K. PBMC transcription profiles of pigs with divergent humoral immune responses and lean growth performance. Int J Biol Sci. 2013;9:907-16.

42. Munyaka PM, Kommadath A, Fouhse J, Wilkinson J, Diether N, Stothard P, et al. Characterization of whole blood transcriptome and early-life fecal microbiota in high and low responder pigs before, and after vaccination for Mycoplasma hyopneumoniae. Vaccine. 2019;37:1743-55.

43. Matthijs AMF, Auray G, Jakob V, García-Nicolás O, Braun RO, Keller I, et al. Systems immunology characterization of novel vaccine formulations for Mycoplasma hyopneumoniae bacterins. Front Immunol. 2019;10:1087.

44. R Core Team. R: a language and environment for statistical computing. Vienna: R Foundation for Statistical Computing; 2019. https://www.r-proje ct.org/

45. Bates D, Mächler M, Bolker B, Walker S. Fitting linear mixed-effects models using Ime4. J Stat Softw. 2015;67:1-48.

46. Kuznetsova A, Brockhoff PB, Christensen RHB. ImerTest package: tests in linear mixed effects models. J Stat Softw. 2017:82:1-26.

47. Lê S, Josse J, Husson F. FactoMineR: a package for multivariate analysis. J Stat Softw. 2008:25:1-18.

48. Groeneveld E, Kovac M, Mielenz N. VCE User's guide and reference manual. Version 6.0. Neustadt: Institute of Farm Animal Genetics; 2008.

49. Rönnegård L, McFarlane SE, Husby A, Kawakami T, Ellegren H, Qvarnström A. Increasing the power of genome wide association studies in natural populations using repeated measures — evaluation and implementation. Methods Ecol Evol. 2016;7:792-9.

50. Langfelder P, Horvath S. WGCNA: an R package for weighted correlation network analysis. BMC Bioinformatics. 2008;9:559.

51. Benjamini Y, Hochberg Y. Controlling the false discovery rate: a practical and powerful approach to multiple testing. J R Stat Soc Ser B. 1995;57:289-300

52. Weiner J 3rd, Domaszewska T. tmod : an R package for general and multivariate enrichment analysis. PeerJ Prepr. 2016;4:e2420v1.

53. Lê Cao K-A, Boitard S, Besse P. Sparse PLS discriminant analysis : biologically relevant feature selection and graphical displays for multiclass problems Sparse PLS discriminant analysis: biologically relevant feature selection and graphical displays for multiclass problems. BMC Bioinformatics. 2011;12:253.

54. Maroilley T, Lemonnier G, Lecardonnel J, Esquerré D, Ramayo-Caldas Y, Mercat MJ, et al. Deciphering the genetic regulation of peripheral blood transcriptome in pigs through expression genome-wide association study and allele-specific expression analysis. BMC Genomics. 2017;18:967.

55. Djordjevic S, Eamens GJ, Romalis LF, Nicholls PJ, Taylor V, Chin J. Serum and mucosal antibody responses and protection in pigs vaccinated against Mycoplasma hyopneumoniae with vaccines containing a denatured membrane antigen pool and adjuvant. Aust Vet J. 1997;75:504-11.

56. Thacker EL, Thacker BJ, Boettcher TB, Jayappa H. Comparison of antibody production, lymphocyte stimulation, and protection induced by four commercial Mycoplasma hyopneumoniae bacterins. Swine Health Prod. 1998:6:107-12.

57. Marchioro SB, Maes D, Flahou B, Pasmans F, Del Pozo SR, Vranckx K, et al Local and systemic immune responses in pigs intramuscularly injected with an inactivated Mycoplasma hyopneumoniae vaccine. Vaccine. 2013;31:1305-11.

58. Stear MJ, Bishop SC, Mallard BA, Raadsma H. The sustainability, feasibility and desirability of breeding livestock for disease resistance. Res Vet Sci. 2001;71:1-7.

59. Tsang JS, Schwartzberg PL, Kotliarov Y, Biancotto A, Xie Z, Germain RN, et al. Global analyses of human immune variation reveal baseline predictors of postvaccination responses. Cell. 2014;157:499-513.

60. Case LK, Wall EH, Dragon JA, Saligrama N, Krementsov DN, Moussawi M, et al. The $Y$ chromosome as a regulatory element shaping immune cell transcriptomes and susceptibility to autoimmune disease. Genome Res. 2013:23:1474-85.

61. Tsui C, Martinez-Martin N, Gaya M, Maldonado P, Llorian M, Legrave NM, et al. Protein kinase $C-\beta$ dictates $B$ cell fate by regulating mitochondrial remodeling, metabolic reprogramming, and heme biosynthesis. Immunity. 2018;48:e5.

62. Watanabe-Matsui M, Muto A, Matsui T, Itoh-Nakadai A, Nakajima O, Murayama K, et al. Heme regulates B-cell differentiation, antibody class switch, and heme oxygenase-1 expression in B cells as a ligand of Bach2. Blood. 2011;117:5438-48.

63. van der Heiden M, Berbers GAM, Fuentes S, van Zelm MC, Boots AMH, Buisman A. An explorative biomarker study for vaccine responsiveness after a primary meningococcal vaccination in middle-aged adults. Front Immunol. 2018;8:1962. 
64. Klein SL, Flanagan KL. Sex differences in immune responses. Nat Rev Immunol. 2016;16:626-38.

65. Klein SL, Marriott I, Fish EN. Sex-based differences in immune function and responses to vaccination. Trans R Soc Trop Med Hyg. 2014;109:9-15

66. Newport MJ, Goetghebuer T, Weiss HA, Whittle H, Siegrist C-A, Marchant A. Genetic regulation of immune responses to vaccines in early life. Genes Immun. 2004;5:122-9.

67. Tan P, Jacobson RM, Poland GA, Jacobsen SJ, Pankratz VS. Twin studies of immunogenicity - determining the genetic contribution to vaccine failure. Vaccine. 2001;19:2434-9.

68. Höhler T, Reuss E, Evers N, Dietrich E, Rittner C, Freitag CM, et al. Differential genetic determination of immune responsiveness to hepatitis $B$ surface antigen and to hepatitis A virus: a vaccination study in twins. Lancet. 2002;360:991-5.

69. Schaid DJ, Haralambieva IH, Larrabee BR, Ovsyannikova IG, Kennedy RB, Poland GA, et al. Heritability of vaccine-induced measles neutralizing antibody titers. Vaccine. 2017;35:1390-4.

70. Duggan D, Zheng SL, Knowlton M, Benitez D, Dimitrov L, Wiklund F, et al. Two genome-wide association studies of aggressive prostate cancer implicate putative prostate tumor suppressor gene DAB2IP. J Natl Cancer Inst. 2007;99:1836-44.

71. Liu L, Xu C, Hsieh JT, Gong J, Xie D. DAB2IP in cancer. Oncotarget. 2016;7:3766-76.

72. Curtis J, Luo Y, Zenner HL, Cuchet-Lourenço D, Wu C, Lo K, et al. Susceptibility to tuberculosis is associated with variants in the ASAP1 gene encoding a regulator of dendritic cell migration. Nat Genet. 2015;47:523-7.

73. Qayyum R, Snively BM, Ziv E, Nalls MA, Liu Y, Tang W, et al. A meta-analysis and genome-wide association study of platelet count and mean platelet volume in African Americans. PLoS Genet. 2012;8:e1002491.
74. Meisinger C, Prokisch H, Gieger C, Soranzo N, Mehta D, Rosskopf D, et al. A genome-wide association study identifies three loci associated with mean platelet volume. Am J Hum Genet. 2009;84:66-71.

75. Astle WJ, Elding H, Jiang T, Allen D, Ruklisa D, Mann AL, et al. The allelic landscape of human blood cell trait variation and links to common complex disease. Cell. 2016;167:e19.

76. Watabe K, Ito A, Asada H, Endo Y, Kobayashi T, Nakamoto K, et al. Structure, expression and chromosome mapping of $M L Z E$, a novel gene which is preferentially expressed in metastatic melanoma cells. Jpn J Cancer Res. 2001;92:140-51.

77. Tamura M, Tanaka S, Fujii T, Aoki A, Komiyama H, Ezawa K, et al. Members of a novel gene family, Gsdm, are expressed exclusively in the epithelium of the skin and gastrointestinal tract in a highly tissue-specific manner. Genomics. 2007;89:618-29.

78. Crosslin DR, McDavid A, Weston N, Zheng X, Hart E, de Andrade M, et al Genetic variation associated with circulating monocyte count in the eMERGE network. Hum Mol Genet. 2013;22:2119-27.

79. Munyaka PM, Blanc F, Estellé J, Lemonnier G, Leplat J-J, Rossignol M-N et al. Discovery of predictors of Mycoplasma hyopneumoniae vaccine response efficiency in pigs: 16S rRNA gene fecal microbiota analysis. Microorganisms. 2020;8:1151.

\section{Publisher's Note}

Springer Nature remains neutral with regard to jurisdictional claims in published maps and institutional affiliations.
Ready to submit your research? Choose BMC and benefit from:

- fast, convenient online submission

- thorough peer review by experienced researchers in your field

- rapid publication on acceptance

- support for research data, including large and complex data types

- gold Open Access which fosters wider collaboration and increased citations

- maximum visibility for your research: over $100 \mathrm{M}$ website views per year

At BMC, research is always in progress.

Learn more biomedcentral.com/submissions 